\title{
Migratory neighbors and distant invaders: tumor-associated niche cells
}

\author{
Jared Wels, ${ }^{1,2,4}$ Rosandra N. Kaplan,, ${ }^{1,2,4}$ Shahin Rafii, ${ }^{2,3,6}$ and David Lyden ${ }^{1,2,5}$ \\ ${ }^{1}$ Department of Pediatrics and Department of Cell and Developmental Biology, Weill Cornell Medical College, \\ New York, New York 10021, USA; ${ }^{2}$ Memorial Sloan-Kettering Cancer Center, New York, New York 10021, USA; \\ ${ }^{3}$ Department of Genetic Medicine, Weill Cornell Medical College, New York, New York 10021, USA
}

The cancer environment is comprised of tumor cells as well as a wide network of stromal and vascular cells participating in the cellular and molecular events necessary for invasion and metastasis. Tumor secretory factors can activate the migration of host cells, both near to and far from the primary tumor site, as well as promote the exodus of cells to distant tissues. Thus, the migration of stromal cells and tumor cells among specialized microenvironments takes place throughout tumor and metastatic progression, providing evidence for the systemic nature of a malignancy. Investigations of the tumor-stromal and stromal-stromal cross-talk involved in cellular migration in cancer may lead to the design of novel therapeutic strategies.

Understanding the complex biological networks at play in metastasis requires a precise detailing of the molecular and cellular pathways involved in local and systemic migration. The long prevailing model of invasion and metastasis has focused on the adhesive and migratory capabilities that are intrinsic to tumor cells (Hanahan and Weinberg 2000). Meanwhile, we are becoming increasingly aware that tumors are composed of genetically altered malignant cells along with a heterogeneous population of stromal cells, whose dynamic interactions can profoundly enhance tumor progression and metastasis. Through the production of chemokines, growth factors, and matrix-degrading enzymes (Table 1), supportive cells-including fibroblasts, immune cells, and bone marrow (BM)-derived stem and progenitor cells-support blood vessel formation, break down basement membrane barriers, and attract tumor cells to distant sites. Tumor cells are constantly giving instructions, not only by direct cell-cell interactions, but also by secreted factors that "activate" normal host cells at both proximal and distal sites to migrate, eventually developing per-

[Keywords: Endothelial cells; invasion; metastasis; migration; stem cell; tumor microenvironment]

${ }^{4}$ These authors contributed equally to this work.

Corresponding authors.

${ }^{5}$ E-MAIL dcl2001@med.cornell.edu; FAX (212) 746-8423.

${ }^{6}$ E-MAIL srafii@med.cornell.edu; FAX (212) 746-8423.

Article is online at http://www.genesdev.org/cgi/doi/10.1101/gad.1636908. missive niches that, in return, promote tumor cell survival and proliferation. The focus of this review is on the cellular constituents of the primary and metastatic tumor microenvironments, with emphasis on their migratory pathways. We hope to convey that the tumor and host cell interaction is truly reciprocal; while host cells may support tumor cells, tumor cells in turn modulate the microenvironments within which they reside. Furthermore, we highlight that cancer is a systemic disease, encompassing collective cell movements of tumor and stromal cells that are a prerequisite for tumor cell invasion and metastasis.

\section{Intrinsic tumor cell migratory capabilities}

Inherent to the metastatic process is the capability of tumor cells to migrate through connective tissue barriers comprising cell-cell adherent junctions, basement membranes, and interstitial tissue stroma. This intrinsic migratory behavior is highly dependent on the interplay between adhesive and proteolytic activities. Tumor cell down-regulation of proteins mediating cell-cell interactions, such as cadherins, leads to changes in cell signaling, actin-based cytoskeletal structure, and eventual dissociation from neighboring cells of the primary tumor (Friedl and Brocker 2000). E-cadherin-based cell-cell contacts are replaced with cell-matrix interactions promoting locomotion resembling either a slow, adhesive fibroblast-like migration or a more dynamic ameboid crawling. Fibroblast-like migration is accompanied by integrin cluster-mediated adherence to matrix fibrils and remodeling of the extracellular matrix (ECM). Alternately, rapid ameboid migration, associated with certain carcinoma cells as well as lymphomas and leukemias, is dependent on ROCK family kinases that promote changes in cell shape to navigate through the dense matrix environment (Friedl and Brocker 2000; Pinner and Sahai 2008). The deposition of proteases such as plasmin and a variety of members of the matrix metalloprotease (MMP) family is essential in tissue remodeling, which favors tumor cell intravasation and dissemination.

Although the importance of the intrinsic migratory ability of tumor cells for promoting metastasis is well 
Wels et al.

Table 1. Significant trafficking molecules found within $B M$ and peripheral niches

\begin{tabular}{ll}
\hline Growth factors & \multicolumn{1}{c}{ Receptors } \\
\hline $\begin{array}{l}\text { Vascular endothelial growth factor-A } \\
\text { (VEGF-A) }\end{array}$ & VEGFR-1, \\
Placental growth factor (PlGF) & VEGFR-1 \\
$\begin{array}{l}\text { Granulocyte colony-stimulating factor- } \beta \\
\text { (G-CSF) }\end{array}$ & G-CSFR \\
Platelet-derived growth factor (PDGF) & PDGFR $\alpha, \beta$ \\
Colony-stimulating factor 1 (CSF-1) & M-CSFR \\
Migration inhibitory factor (MIF) & CD74 \\
Fibroblast growth factor (FGF) & FGFR1-4 \\
Hepatocyte growth factor (HGF) & c-Met \\
Epidermal growth factor (EGF) & EGFR \\
Angiopoietin-1,-2 & Tie-2 \\
Brain-derived neurotrophic factor (BDNF) & LNGFR, TrkB \\
Osteopontin & CD44, VLA-4, $\alpha_{\mathrm{V}} \beta_{3}$ \\
Insulin growth factor (IGF-1) & IGF-I/IIR \\
\hline Chemokines & \\
\hline Stromal-derived factor (SDF-1/CXCL12) & CXCR4, CXCR7 \\
Transforming growth factor $\beta$ (TGF- $\beta$ ) & TGF- $\beta R$ I/II \\
CC chemokine ligand 2 (CCL2/MCP-1) & CCR2 \\
CCL5 & CCR1, 3, 4, 5 \\
CXCL8/IL-8 & CXCR1, 2 \\
CXCL1/MIP-2 & CXCR1, 2 \\
CCL22 & CCR4 \\
CCL12 & CXCR4, CXCL12, \\
IL-10 & CCR2 \\
S100A8/9 & IL-10R1, 2 \\
S100A4 & CD36, LTB4 \\
& S100A4R, HSPG, \\
& annexin II \\
\hline Proteases & \\
\hline &
\end{tabular}

Proteases

MMP-1,2,3,9,11,14

uPA

recognized, the contribution of the tumor microenvironment including its various cellular constituents also provides essential signals that regulate tumor cell invasion and migration. In addition, we are just beginning to appreciate the similarities in migratory characteristics between tumor and stromal components of cancer. These cellular transit pathways are essential for an exchange of information, providing necessary signals to prepare and promote tumor progression. This allows for global communication between local and distant microenvironments and involves cellular adaptation to promote survival and growth at far-away sites. Components of this environment include local stromal cells, such as resident fibroblasts and macrophages, and distant recruited cells such as endothelial cells, immune cells, and BM-derived precursor cells, as well as circulating platelets that can communicate between BM, tumor, and distant tissue sites. Here we discuss the cellular constituents of the tumor microenvironment, actively migrating from sites both local and distant that contribute to enhanced tumor cell motility, invasiveness, and survival (Fig. 1).

\section{Migratory neighbors support primary tumor growth}

\section{Predominant residents: fibroblasts help make the move}

Fibroblasts constitute the majority of stromal cells within the primary tumor bed in various types of human carcinomas (Sappino et al. 1988). Until recently, the role of these cells in tumor progression was unknown. As with fibroblasts associated with wound healing, carcinoma-associated fibroblasts (CAFs) are referred to as "activated fibroblasts," or myofibroblasts (Olumi et al. 1999|, and are characterized by the production of $\alpha$-smooth muscle actin. The role of CAFs in tumor progression was highlighted by several experiments demonstrating that fibroblasts in tumor stroma have unique cancer-promoting properties compared with fibroblasts elsewhere in the body. Early studies determined the effect on tumor progression after analyzing grafts of tumorigenic epithelial cells mixed with either normal fibroblasts or fibroblasts that were immortalized, transformed, or tumor-associated (Camps et al. 1990; Gleave et al. 1991; Atula et al. 1997). More recent studies in which CAFs were coimplanted with nontumorigenic prostate epithelial cells showed that these activated fibroblasts could induce tumorigenesis in immunocompromised mice (Hayward et al. 2001). Similarly, CAFs isolated from invasive human breast carcinomas were shown to be more competent than normal fibroblasts in promoting growth of breast cancer cells in a murine model of breast carcinoma (Orimo et al. 2005). This effect was shown to be largely due to increased secretion of the stromal-derived chemokine stromal-derived factor-1 (SDF-1) by fibroblasts. SDF-1 can enhance tumor progression by directly stimulating the growth of carcinoma cells expressing its cognate receptor, CXCR4, and by initiating the recruitment of angiogenesis-enhancing $\mathrm{CXCR}^{+}$endothelial progenitor cells (EPCs) (Orimo et al. 2005). The SDF-1-CXCR4 axis utilized by activated fibroblasts also directly promotes tumor cell motility based on chemokine gradients of SDF-1 and CXCR4 expression on most tumor cells.

Besides the role of the SDF-1-CXCR4 axis, relatively little is known about the molecular determinants that enable CAFs to promote tumor and stromal cell migration. In response to tumor cell stimulation, the production of fibronectin, a key extracellular adhesion molecule, may increase, promoting the migratory capability of fibroblasts themselves as well as certain tumor types. Various fibronectin isomers arise through alternate splicing of three exons from one gene locus. During normal physiology, fibronectin isoforms, including extra domain A (ED-A) and extra domain B (ED-B) regions, are expressed at low levels; however, pathological conditions can significantly up-regulate isoforms containing these domains. As such, invasive tumors are well known to express isoforms containing ED-A and ED-B domains (Oyama et al. 1989; Midulla et al. 2000; Castellani et al. 2002; Mhawech et al. 2005). A unique truncated isoform of fibronectin has also been shown to be produced by 
A) Stromal cell recruitment during angiogenesis and invasion

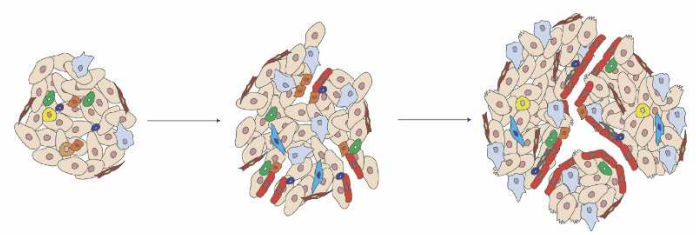

B) Stromal cell recruitment at secondary metastatic sites
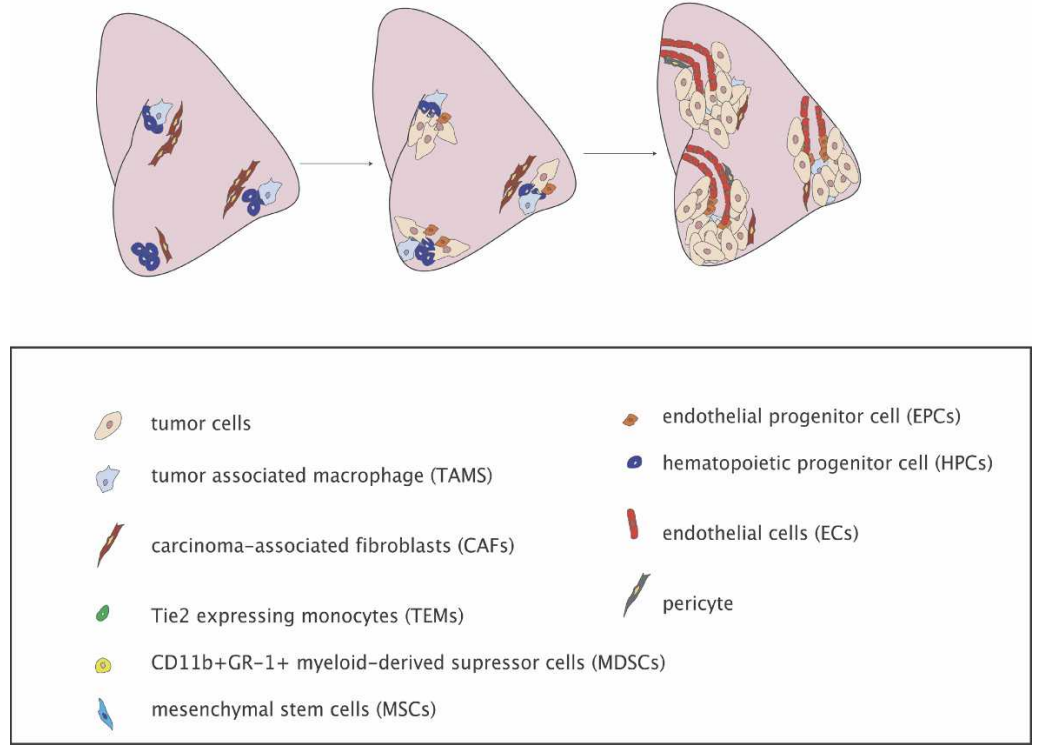

Figure 1. Stromal cell recruitment at primary and metastatic sites. (A, top left) Early-stage stromal cell recruitment at the primary tumor includes immune infiltrates such as TEMs, TAMs, BMDCs (HPCs and EPCs), MDSC cells, and recruited CAFs. (Top middle) The production of matrix proteases and secretion of proangiogenic chemokines promotes local endothelial cell proliferation and chemotaxis. Blood vessel maturation is promoted via pericyte investment at vascular endothelium, although vessels remain leaky and disorganized. (Top right) Intravasation of tumor cells into the circulation, as well as invasion into surrounding tissue, is mediated by paracrine signaling exchange between fibroblasts, macrophages, and tumor cells. $(B$, bottom left) Stromal cell alterations at distant future metastatic organs include the activation of fibroblasts and the recruitment of HPCs and myeloid precursor cells. (Bottom middle) The secretion of inflammatory chemokines and matrix-degrading enzymes results in tumor cell adherence and proliferation at these sites. (Bottom right) Finally, the acquisition of blood supply via EPC and EC recruitment results in the progression of micrometastatic to macrometastatic disease. embryonic fibroblasts and CAFs and is capable of inducing both tumor and fibroblast cell migration (Schor et al. 2003). These studies suggest an active role of distinct fibronectin isoforms in promoting tumor and CAF migration.

It is still under debate whether these stromal fibroblasts are recruited into the tumor and subsequently activated by tumor cells into myofibroblasts in order to support growth, or alternatively, tumor progression is accelerated as a physiological response to a previously altered resident stromal environment (Farber 1984; Barcellos-Hoff 1998; Tlsty 1998; Bissell and Radisky 2001). CAFs may be derived from several different mobilized cell types, including normal fibroblasts, preadipocytes, smooth muscle cells, or BM-derived cells (BMDCs) (Ishii et al. 2003; Direkze et al. 2004). It is also apparent that there may be several different fibroblast populations associated with tumors with both overlapping and nonoverlapping expression patterns of markers such as $\alpha$ SMA, PDGFR $\beta$, and NG2 (Sugimoto et al. 2006). These different sets of markers most likely delineate unique cellular populations, including myofibroblasts and pericytes, with separate functions in tumor progression. Understanding the molecular events for the generation of CAFs from normal fibroblasts in either distant or local environments is one of the queries that remain unresolved.

\section{Infiltrating inflammatory cells}

One of the most well-characterized types of tumor-infiltrating inflammatory cells is the macrophage, or tumorassociated macrophage (TAM) (Nagasawa et al. 1996). Since the late 1970s, the infiltration of TAMs has been well documented and, for the most part, associated with poor prognosis. TAMs associated with solid tumor tissue have been reported to constitute up to $50 \%$ of the tumor mass and have strong implications in tumor progression and metastasis (Kelly et al. 1988; Leek et al. 1994). Colony-stimulating factor 1 (CSF-1) is the main growth factor associated with macrophage survival, proliferation, differentiation, and chemotaxis. Importantly, CSF1-deficient mice lack macrophages and have significantly lower rates of tumor progression and metastasis formation in models of breast cancer (Lin et al. 2001). In breast cancer patients, CSF-1 was expressed significantly in $74 \%$ of the tumors associated with poor prognosis (Scholl et al. 1994). Thus, recruitment of TAMs to tumor sites via CSF-1 and other chemokines appears to be crucial for tumor progression in many types of cancers (Pollard 2004).

The role of TAMs at the primary tumor is multifaceted and, in many cases, provides a supportive environment for pre-existing malignant cells. However, there is an increasing amount of evidence supporting the role of 
Wels et al.

TAMs in stimulating tumor growth and inducing oncogenic mutations in surrounding epithelial cells associated with the earliest stages of carcinogenesis. Indeed, TAMs are likely recruited to tumor sites as a part of an innate immune response, and their continuous presence parallels chronic inflammation, which can be a causative event for many types of cancer. TAMs can produce high amounts of reactive compounds, including reactive oxygen and nitrogen species that can interact with DNA, inducing mutations in surrounding epithelium (Maeda and Akaike 1998; Lin et al. 2001). This property may explain mutations seen in local tumor endothelium and stromal cells (Pelham et al. 2006). Alternatively, TAMs can produce cytokines that are capable of inducing genetic abnormalities. For instance, generation of migration inhibitory factor (MIF) suppresses p53 transcription in tumor cells, resulting in defective DNA damage repair and the accumulation of genetic mutations (Hudson et al. 1999). TAMs can also produce several growth factors capable of directly promoting the growth of tumor cells. These include fibroblast growth factor (FGF), hepatocyte growth factor (HGF), epidermal growth factor (EGF), platelet-derived growth factor (PDGF), and transforming growth factor- $\beta$ (TGF- $\beta$ ) (Pollard 2004). EGF appears to be especially important in many types of cancers, including breast cancer, in which it has been shown to enhance tumor-cell migration via direct regulation of integrinbinding focal adhesion proteins, tensin-3 and cten (Katz et al. 2007). Together, these studies provide a substantial link between inflammation associated with macrophage infiltration and tumorigenesis.

As the number of studies on TAMs grows, it has become clear that characteristics bestowed upon TAMs in the literature likely describe a heterogeneous population of cells whose common origin is still controversial. Likely precursors of TAMs are monocytes that are actively recruited to the tumor from the blood. Monocytes were originally shown to be recruited to these sites in response to a tumor-derived chemokine, $\mathrm{CC}$ chemokine ligand 2 (CCL2/MCP-1), where they then differentiated into TAMs (Mantovani et al. 2002). Subsequent studies have identified additional factors involved in attracting monocytes to the tumor. Chemokines such as CCL2, CCL5, CXCL8/IL-8, and SDF-1 expressed by tumor cells, fibroblasts, endothelial cells, and TAMs act as monocyte chemoattractants (Murdoch et al. 2004). Cytokines and growth factors, including CSF-1, vascular endothelial growth factor-A (VEGF-A), and placental growth factor (PlGF) have also been implicated in initiating monocyte infiltration (Barleon et al. 1996; Goswami et al. 2005; Nakao et al. 2005). In addition to promoting cell migration of peripheral monocytes to the tumor microenvironment, certain chemoattractants may also indirectly enhance monocyte infiltration through indirect means. For instance, both CCL2 and CCL5 have been shown to stimulate monocytes to secrete MMP-9, MMP-19, and uPA, which act to degrade the basement membrane and ECM components to further promote monocyte infiltration (Cross and Woodroofe 1999; Azenshtein et al. 2002; Locati et al. 2002; Robinson et al. 2002). The accumula- tion of TAMs into hypoxic regions of tumors is well documented and is likely regulated by a hypoxic-mediated chemoattractive gradient involving hypoxia-inducible factor 1 (HIF-1)-induced growth factors such as VEGF (Murdoch et al. 2004). Not surprisingly, high expression of monocyte chemoattractants is associated with increased macrophage infiltration (Sica et al. 2006). Thus, strategies to prevent TAM migration to the tumor microenvironment are under investigation. Recent work has implicated angiostatins in inhibiting TAM recruitment, acting to block migration by disruption of actindriven filipodia and lamellipodia (Perri et al. 2007). Alternately, given the ability of macrophages to home into the tumor microenvironment, several studies have aimed to use TAMs as delivery vehicles for anti-tumor genes including IFN- $\gamma, C S F-1$, or the immunosuppressive and antiangiogenic cytokine $I L-10$ (Murdoch et al. 2004).

\section{Recruited stromal players in angiogenesis}

The expansion of a tumor mass beyond a microscopic size is dependent on its ability to obtain its own blood supply. Tumor vasculature can be developed through angiogenesis, the sprouting of new blood vessels, or cooption of pre-existing vessels (Hanahan and Folkman 1996). The formation of new vessels within the tumor requires the proliferation and directional migration of endothelial cells through basement membrane and perivascular stroma toward proangiogenic stimuli. Endothelial cell migration occurs via chemotaxis (migration toward a gradient of soluble chemoattractants such as VEGF-A, bFGF [FGF-2], or angiopoietins), haptotaxis (migration toward a gradient of immobilized ligands present in the ECM), and/or mechanotaxis (migration activated in response to fluid shear stress induced by blood flow) (Lamalice et al. 2007). Lymph vessel recruitment is also a critical factor in metastatic spread, as many types of cancers first metastasize to sentinel lymph nodes. VEGF-C-dependent lymphangiogenesis at the primary tumor as well as the expansion of vessel networks at distant lymph nodes appear to set the stage for lymphatic tumor spread (Hirakawa et al. 2005, 2007; Harrell et al. 2007). In addition to endothelial and lymphatic cell migration, there are accumulating reports implicating the involvement of numerous cell types that play a role in blood vessel development, support, and growth, including monocytes, TAMs, and pericytes (Fig. 1A). Furthermore, these general mechanisms of endothelial cell movement are likely utilized by other cells such as fibroblasts, immune cells and pericytes.

\section{Pericytes promote angiogenesis via blood vessel stabilization}

Pericytes are multifunctional cells that closely associate with the abluminal side of vascular endothelium through many tight cell-cell contacts that maintain microvessel stability. During angiogenesis, pericytes are recruited to sites of newly forming vessels through an extracellular gradient of PDGF (PDGF-B) (Abramsson et al. 
2003). However, in contrast to pericytes associated with physiological vessels, pericytes associated with tumor vessels are less abundant and exhibit an abnormal phenotype. This abnormality contributes to the leakiness associated with neovessels (Jain and Booth 2003), however, it is generally agreed that pericytes play a supportive role. Accordingly, pericytes recently have become an attractive target for anti-angiogenic therapy (Jain and Booth 2003; Baluk et al. 2005). Indeed, by blocking VEGF-A and PDGF pathways, studies combining target strategies for both endothelial cells and pericytes have shown promising anti-tumor and anti-angiogenic effects (Bergers et al. 2003). These blocking studies illustrate the critical and complex role that pericytes play in tumor progression and suggest that there may be yet-unknown mechanisms that these cells possess to promote tumorigenesis.

\section{Inflamed players in angiogenesis}

TAMs have also been shown to regulate the switch of a tumor to an angiogenic stage. Although anti-angiogenic functions of macrophages have been reported, TAMs generally play a proangiogenic role. In the polyoma middle $\mathrm{T}$ oncoprotein model of mammary tumors, a significant infiltration of macrophages occurs at stages directly preceding those changes associated with angiogenesis (Lin et al. 2003). When given tumors, mice deficient in macrophages, through genetic deletion of the CSF-1 gene, manifest a delayed angiogenic switch (Lin et al. 2006). TAMs are an important producer of VEGF-A within the tumor (Leek et al. 2000; Lewis et al. 2000), which may be regulated by hypoxia as well as CSF-1 activation. Transgenic mice made to express GFP under the control of the human VEGF-A promoter illustrate that both stromal cells as well as BM-derived macrophages are a large source of this growth factor (Fukumura et al. 1998). The release of MMPs that break down the ECM also serves as a mechanism to release bound VEGFA. TAMs synthesize urokinase-type plasminogen activator (uPA), which acts to break down the ECM and may also serve to function during vascular remodeling (Hildenbrand et al. 1995). TAMs tend to infiltrate regions of poor vascularization, which induces transcriptional activation of HIF-1- and HIF-2-regulated promoters, resulting in the up-regulation of proteins such as VEGF-A, MMPs, interleukins, and chemokines. Thus, it appears that TAMs not only function to promote vascular sprouting through the direct or indirect release of angiogenic factors, but also provide enzymes capable of vascular remodeling after vessel formation.

A population of peripheral, tumor-infiltrating monocytes, considered precursors to TAMs, has been shown to play an essential role in angiogenesis as well. Monocytes expressing the angiopoietin receptor Tie2, referred to as Tie2-expressing monocytes (TEMs), associate closely with tumor blood vessels. Elimination of TEMs by means of a suicide gene significantly impairs tumor growth and vascularity in mouse glioma models (De Palma et al. 2005). Although the molecular mechanisms behind the proangiogenic role of TEMs need to be elucidated, the human counterpart of TEMs has been identified recently in the peripheral blood of cancer patients, with angiogenic activity in xenotransplanted human tumors (Venneri et al. 2007). Thus, TEMs represent a distinct myeloid subpopulation of monocyte/macrophages that may prove to be an attractive anti-angiogenic target.

\section{Young and restless: BM-derived precursors in angiogenesis}

EPCs are BMDCs mobilized in response to chemotherapy, injury, ischemia, or tumor growth (Kopp et al. 2006). During early stages of tumor growth, cytokines, including VEGF-A, act to mobilize EPCs from the BM to become circulating endothelial progenitor cells (CEPs), ultimately infiltrating and incorporating into the newly forming tumor vasculature (Lyden et al. 2001). Although still under debate, the cell surface antigens used to identify these cells include markers for primitive hematopoietic cells as well as endothelial cells including c-kit, CD133, Sca-1, VE-cadherin, VEGFR-2, and endoglin (Rafii and Lyden 2003; Kopp et al. 2006; Case et al. 2007). The identity and relative contribution of EPCs to newly forming tumor vasculature have been less obvious in certain tumors, with some reports detecting only minimal contribution to tumor vessels /Voswinckel et al. 2003; Gothert et al. 2004; He et al. 2004; Ziegelhoeffer et al. 2004; De Palma et al. 2005; Kopp et al. 2006). However, recent reports have provided further evidence supporting the involvement of these cells in early blood vessel development during neoangiogenesis (Nolan et al. 2007; Gao et al. 2008). Using genetically marked $\mathrm{GFP}^{+} \mathrm{BM}$ cells in a series of BM transplantation experiments, Nolan et al. (2007) have demonstrated that BM-derived EPCs, as defined by $\mathrm{GFP}^{+}$VE-cadherin ${ }^{+} \mathrm{CD} 31^{\text {low }}$ $\mathrm{CD}_{1} 1 \mathrm{~b}^{-}$, comprise $\sim 25 \%-35 \%$ of total endothelium during the early stages of tumor growth. High-resolution confocal micrography was used to show physical incorporation of EPCs in three separate syngeneic as well as one spontaneous tumor model. Finally, specific targeting of EPCs with an $\alpha$-particle-emitting antibody for VE-cadherin, which fails to target mature endothelial cells, impaired tumor growth and reduced levels of vascularization (Nolan et al. 2007). These reports confirm that, at least in the early phases of angiogenesis, BM-derived EPCs are a critical component of the forming vasculature.

Just as the up-regulation of local chemoattractants within the BM microenvironment leads to tumor cell homing and retention within the bone, the release of secreted growth factors and chemokines by the tumor also results in the proliferation and recruitment of BMderived accomplices to support angiogenesis and metastasis. In addition to VEGF-A, tumor cells may also secrete PlGF, which signals exclusively through VEGFR-1 and is associated with more aggressive disease (Li et al. 2006). VEGF receptor signaling directs tumor growth and angiogenesis, recruiting VEGFR-1 $1^{+}$hematopoietic progenitor cells (HPCs) in addition to VEGFR-2 $2^{+}$EPCs to 
neoangiogenic sites in the tumor (Lyden et al. 2001). The necessity of both HPCs and EPCs for tumor vasculature is demonstrated in the angiodeficient Id (inhibitor of differentiation) mutant mouse model, which is resistant to tumor progression due to a failure of BM progenitor mobilization and consequential defective angiogenesis. Transplantation of wild-type BM or VEGF-mobilized stem cells restores tumor angiogenesis and growth in this model (Lyden et al. 1999). In addition to EPC incorporation into neovessels, VEGFR-1 $1^{+}$HPCs also appear to lie in close association with forming vasculature. Indeed, VEGFR-1 inhibition diminished investment of vessels with perivascular cells, suggesting that VEGFR-1 ${ }^{+}$HPCs confer vessel stability and promote tumor progression. One mechanism by which HPCs may promote angiogenesis is by the paracrine release of angiogenic factors, thereby enhancing the recruitment and incorporation of EPCs to new tumor vessels (Grunewald et al. 2006). Activated HPCs can release angiogenic factors such as VEGF-A, PDGF, angiopoietins, and brain-derived neurotrophic factor (BDNF), which serve to enhance vessel formation and stability (Donovan et al. 2000; Otani et al. 2002; Okamoto et al. 2005).

There is evidence that other BM-derived immature cells such as immunosuppressive $\mathrm{CD} 11 \mathrm{~b}^{+} \mathrm{GR} 1^{+}$myeloid cells may also contribute to neovascularization. Presently referred to as myeloid-derived suppressor cells (MDSCs), these undifferentiated myeloid cells, expressing CD11b and Gr-1, accumulate rapidly in the primary tumor microenvironment (Bronte et al. 1999; Melani et al. 2003; Kusmartsev et al. 2004; Sinha et al. 2005; Sica and Bronte 2007). Inherent anti-VEGF refractoriness is associated with infiltration of $\mathrm{CD} 11 \mathrm{~b}^{+} \mathrm{Gr}^{+}$cells, which indirectly promotes and stabilizes new blood vessels in the primary tumors (Shojaei et al. 2007). Several studies also support the notion that MDSC precursors can infiltrate tumors and differentiate into $\mathrm{F} 4 / 80^{+} \mathrm{TAMs}$, furthering support for their proangiogenic role (Kusmartsev et al. 2004, 2005). In addition, MDSCs have also been shown to have a profound effect on immune evasion of tumors in their undifferentiated state. As a mixture of immature monocytic and granulocyte populations, these cells have high potential to suppress immune response both in vitro and in vivo (Kusmartsev and Gabrilovich 2006; Sica and Bronte 2007).

\section{Stromal-tumor cell interactions that promote invasion and metastasis}

The interplay of tumor cells and stromal fibroblasts at the invasive front can result in distinct migratory signals for both cell types. Also, tumor cells that have acquired genetic alterations can confer signals that enhance migration of local tumor-associated host cells as well as in distant sites such as the BM.

\section{CAFs and the epithelial-to-mesenchymal transition (EMT)}

In addition to promoting angiogenesis and the proliferative capacity of tumor cells, CAFs have been implicated in enhancing tumor cell invasiveness, possibly through the induction of EMT. EMT, associated with the loss of E-cadherin-based cell adhesions and the acquisition of migratory and invasive properties, is now well recognized as a key determinant for cancer progression. Although cell-autonomous mechanisms for EMT exist, several exogenous factors have been shown to promote EMT of carcinoma cells, many of which are produced by CAFs (Bhowmick et al. 2004; Mueller and Fusenig 2004; Kalluri and Zeisberg 2006). Breast carcinoma cells incubated with CAF-conditioned media have been characterized by a loss of E-cadherin-dependent adhesion and enhanced motility (Lebret et al. 2007). Growth factors such as FGF, HGF, and members of the TGF- $\beta$ superfamily, all of which are produced by CAFs, have been shown to be important stimuli of EMT (Lochter et al. 1997; Muller et al. 2002; Thiery 2002; Kalluri and Zeisberg 2006). In addition, the secretion of fibroblast-derived matrix-degrading enzymes plays an essential role in EMT and subsequent tumor invasion. MMP-1, MMP-2, MMP-3, MMP9, MMP-11, MMP-14, and uPA have all been shown to be secreted by fibroblast-like cells in the tumor microenvironment in mouse models, serving to mediate the breakdown of basement membrane barriers (Okada et al. 1995; Heppner et al. 1996; Friedl and Brocker 2000; Stuelten et al. 2005). MMP-3, in particular, is highly expressed in activated fibroblasts and has been shown to promote normal epithelial cells to undergo EMT via cleavage of the extracellular domain of E-cadherin (Lochter et al. 1997). MMP-1 has also been shown to promote tumor cell migration and invasion by cleaving and activating the protease-activated receptor PAR1 expressed in breast carcinoma cells (Boire et al. 2005).

\section{Undifferentiated BM cells: mesenchymal stem cells (MSCs) and CD11b+ GR-1 $1^{+}$MDSCs}

MSCs are pluripotent BMDCs that give rise to a variety of connective tissue cell types including those that form bone, adipose, cartilage, and muscle (Pittenger et al. 1999). Recent studies have shown that BM-derived MSCs are recruited in significant number to primary tumor sites and contribute to invasion and metastasis of several tumor cell lines (Hall et al. 2007; Karnoub et al. 2007). Using a human breast cancer xenograft model, Weinberg and colleagues (Karnoub et al. 2007) have shown that the metastatic potential of breast cancer cell lines becomes greatly enhanced when coinjected with MSCs. Karnoub et al. (2007) demonstrated that paracrine signaling events induce a transiently enhanced metastatic capability in tumor cells, suggesting that metastatic and invasive phenotypes are contextual and require direct MSC association. Specifically, MSC-derived CCL5 appears to be an essential factor, as shRNA knockdown of its receptor (CCR5) in tumor cells abrogates metastasis formation. Although overexpression of CCL5, an important chemokine involved in monocyte/ macrophage recruitment, appears not to affect the levels of macrophage investment at the primary tumor site, it will be interesting to determine the effect of MSC-de- 
rived CCL5 expression on other CCR5-expressing stromal cells at distant secondary sites.

Convincing evidence supporting the role of another immature BMDC type, CD11 $\mathrm{b}^{+} \mathrm{Gr}-1^{+}$MDSCs, in tumor invasion and metastasis has emerged recently. Using a mammary carcinoma model lacking the type II TGF $\beta$ receptor gene, Moses and colleagues (Yang et al. 2008) have demonstrated a significant infiltration of MDSCs at the tumor invasive front. These cells appear to be recruited via SDF-1/CXCR4 and CXCL5/CXCR2 axes and contribute to tumor invasion through metalloproteinase secretion (Yang et al. 2008). Given the implications of CD1 $1 \mathrm{~b}^{+}$GR- $1^{+}$MDSCs in suppressing tumor immunosurveillance, angiogenesis, and tumor invasion, targeting the homing or function of this cell type may prove to be therapeutically effective.

\section{TAMs break down barriers and elicit movement}

In later stages during tumor progression, tumor cells must break down basement membrane and ECM components that act to provide structural integrity in order to invade surrounding tissue and intravasate into the circulation. Macrophages have been reported to be present at high frequency at the invasive front, where the breakdown of ECM occurs (Fig. 1A). TAMs accomplish this by secreting several MMPs, including MMP2 and MMP9, which degrade matrix components such as collagen, laminin, and fibronectin. They can also secrete several other factors-such as TGF $\beta$, urokinase plasminogen activator, tissue-type plasminogen activator, and cathepsins-that also play a role in the degradation of the ECM.

In addition to secreting proteases and factors to break down the ECM, macrophages have been shown to directly promote the invasion of tumor cells. Multiphoton imaging techniques have been used to directly visualize the interaction between tumor cells, macrophages, and surrounding blood vessels (Condeelis and Segall 2003; Wyckoff et al. 2007). These studies have suggested that tumor cells are attracted to macrophages lying in close association with vessels. This attraction is thought to be mediated through a paracrine signaling loop between tumor cells and macrophages, where tumor cells secrete CSF-1, leading to macrophage secretion of EGF, which acts as a chemoattractant for tumor cells (Goswami et al. 2005). Inhibiting either CSF-1 or EGF signaling blocks the migration of both cell types in vivo. Thus, it is believed that activated CSF-1/EGFR signaling induces coordinated polarization and cell migration of both macrophages and tumor cells. These studies may help explain why high expression of CSF-1 in patients correlates with poor outcome (Scholl et al. 1994). A similar paracrine loop is likely involved between tumor cells and activated fibroblasts within the tumor. This is shown in irradiated fibroblasts, where coinjection with lung, mammary, or pancreatic epithelial cells can alter the growth factor profile of the fibroblasts with a concomitant increase in the invasiveness of tumor cells (Barcellos-Hoff and Ravani 2000; Bhowmick et al. 2004; Ohuchida et al. 2004).

\section{Pericytes suppress intravasation}

Pericytes help maintain relative vascular integrity during angiogenesis, and studies have implicated pericytes as negative regulators of metastasis. Xian et al. (2006) show that mice deficient in neural cell adhesion molecule (NCAM), which do not normally produce metastases in the RIP-TAG model of tumorigenesis, develop metastases to distant organs and lymph nodes due to deficiencies in pericyte recruitment and function. After manipulating NCAM expression in two independent tumor models, Xian et al. (2006) found that NCAM production by tumor cells is essential for pericyte recruitment and integration into vessel walls. Importantly, pericyte function appeared to correlate with levels of metastases in both models. Furthermore, tumors implanted in mice deficient in PDGF-B, which have disrupted pericyte recruitment, show enhanced metastatic progression. Thus, these experiments provide compelling evidence supporting the role of pericytes in preventing tumor metastasis. Given the opposing roles of pericytes in angiogenesis and metastasis, therapeutic targeting of these cells may be a double-edged sword and may only prove beneficial in the right temporal conditions.

\section{The platelet shuttle}

Platelets, in addition to immune and endothelial cells, may play an important role in tumor metastasis. The first event in tumor cell invasion at distant sites is lodgment at and adhesion to the local vasculature, and the formation of platelet microthrombi has been implicated in this process. Platelets may encompass disseminating tumor cells while in the circulation, acting as a "shield" to prevent immune attack. More recently, platelets have emerged as key players in directing homing and retention signals for BMDCs and tumor cells. Platelet-deployed SDF- $1 \alpha$ was shown to be critical for the recruitment and retention of CXCR $4^{+}$HPCs and EPCs in revascularization of ischemic tissue and to sites of tumor angiogenesis (Jin et al. 2006). Local activation and release of SDF- $1 \alpha$ by platelets may also govern migration patterns of CXCR4 $4^{+}$tumor cells (Jin et al. 2006; Massberg et al. 2006). Furthermore, platelets are major storage vehicles for both pro- and anti-angiogenic factors (Mohle et al. 1997; Li et al. 2001; Kopp and Rafii 2007). Megakaryocytes and platelets carry the potent natural anti-angiogenic factor thrombospondin, identified as a determinant of the angiogenic phenotype. In keeping with the cell movement from primary tumor to distant metastatic sites and mobilization of immune cells from the BM to each of these sites, platelets may shuttle growth factors from one site to the other. This mechanism further connects these sites while transmitting malignant phenotype from normal mechanisms into pathological ones, thus confirming the systemic nature of these processes.

\section{Collective cell movement: making tracks}

The dialog between tumor cells and stroma conferring migratory properties raises the possibility of a collection 
of cells, including tumor cells and stroma, moving in concert from the primary tumor site to new metastatic stations. It has been recently suggested that stromal fibroblasts and endothelial cells may acquire genetic alterations similar to those seen in tumor cells and this coevolution may provide growth and migratory advantages to both cell types (Pelham et al. 2006). In vivo, migrant cell clusters retain cell-cell junctions, protrude into adjacent tissue driven by leading "pathfinder" cells, and can be detected in lymphatic vessels (Carr 1983) and in peripheral blood (Liotta et al. 1976; Brandt et al. 1996; Friedl and Brocker 2000). Such coordinated cell migration of neoplastic cell clusters from primary explants can also be visualized using time-lapse videomicroscopy in three-dimensional (3D) collagen matrices (Friedl et al. 1995). Additionally, an intriguing study by Gaggioli et al. (2007) has uncovered a key mechanism by which these stromal "pathfinder" cells and invasive tumor cells interact. Using an in vitro 3D organotypic culture, Gaggioli et al. (2007) observed that fibroblasts enable collective invasion of squamous cell carcinoma (SSC) cells by both proteolytic and structural modification of the ECM, thus creating a path through which cancer cells can travel (Gaggioli et al. 2007). Proteolysis of the ECM by fibroblasts appears to be dependent on $\alpha_{3}$ and $\alpha_{5}$ integrins as well as Rho regulation of myosin light chain (MLC) activity (Gaggioli et al. 2007). Further evidence supporting the idea of leading cells paving the way for collective tumor cell migration was provided by studies using time-resolved confocal microscopy by Wolf et al. (2007). These authors showed that the collective invasion of HT-1080 fibrosarcoma cells involves anterior physical fibrillar collagen matrix remodeling and posterior proteolytic fiber breakdown by leading cells, ultimately resulting in the production of an oriented scaffold (Wolf et al. 2007). This collagen scaffold can then be used by chains of following cells. Collectively, these studies support a model for multicellular migration of tumor cells involving either tumor or stromal cell-mediated generation of a pathway by which following groups of tumor cells can travel.

\section{Activation and mobilization at distal sites}

\section{Changes in the BM microenvironment}

Cancer cells secrete a multitude of chemokines and growth factors that not only induce changes in local tumor stroma, but also direct significant changes in the BM microenvironment. An intricate vascular network and a dense mesenchymal-derived stroma cell scaffold exist within the BM. The stromal matrix includes many essential growth factors, cytokines, chemokines, and ECM components that regulate HSC/HPC proliferation and differentiation, a process that can be intensely amplified during tumor burden.

There is a significant amount of overlap in the molecular machinery between metastasizing tumor-initiating cancer cells and physiological HSCs. Therefore, it is not surprising that many cancers show a proclivity to establish in bone and BM, the natural home of HSCs (Fig. 2). Throughout development and the adult life span, the SDF-1 chemokine receptor axis is the master regulator of HSC/HPC homing and retention, both within the BM and at sites in the periphery (Nagasawa et al. 1996; Ara et al. 2003; Dar et al. 2005). As with genetic profiling, specific chemokine repertoires may predict tissue-specific tropism in tumor metastasis. SDF-1 gradients mediate HSC retention within BM niches, and growing evidence suggests that CXCR4-expressing cancer cells home to bone in a similar fashion, where they may lodge in the pre-existing supportive stromal microenvironment (Muller et al. 2001; Kaifi et al. 2005). Bone expresses particularly high levels of SDF-1, and osteotropic cancers such as breast, ovarian, prostate, and neuroblastoma metastasize to bones in a CXCR4-dependent manner (Ge-
Figure 2. Niche-to-niche migration of BM and tumor cells. The transit of BM and tumor cells from their respective niches is a multidirectional pathway. Hematopoietic cells are mobilized from the BM niche in response to tumor-secreted chemokines and subsequently home to both the primary tumor microenvironment and peripheral niches. BMDCs homing to the primary tumor niche may remain in an undifferentiated state in the form of HPCs, EPCs, MSCs, or GR-1 ${ }^{+}$

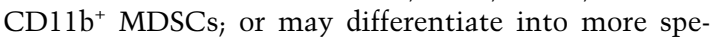
cialized cell types including TAMs. Early BMDCs in transit to premetastatic peripheral niches likely possess an undifferentiated status as HPCs or myeloid-precursor cells, and at later stages involve homing of EPCs. Metastasizing tumor cells subsequently travel to peripheral niches occupied by BMDCs.

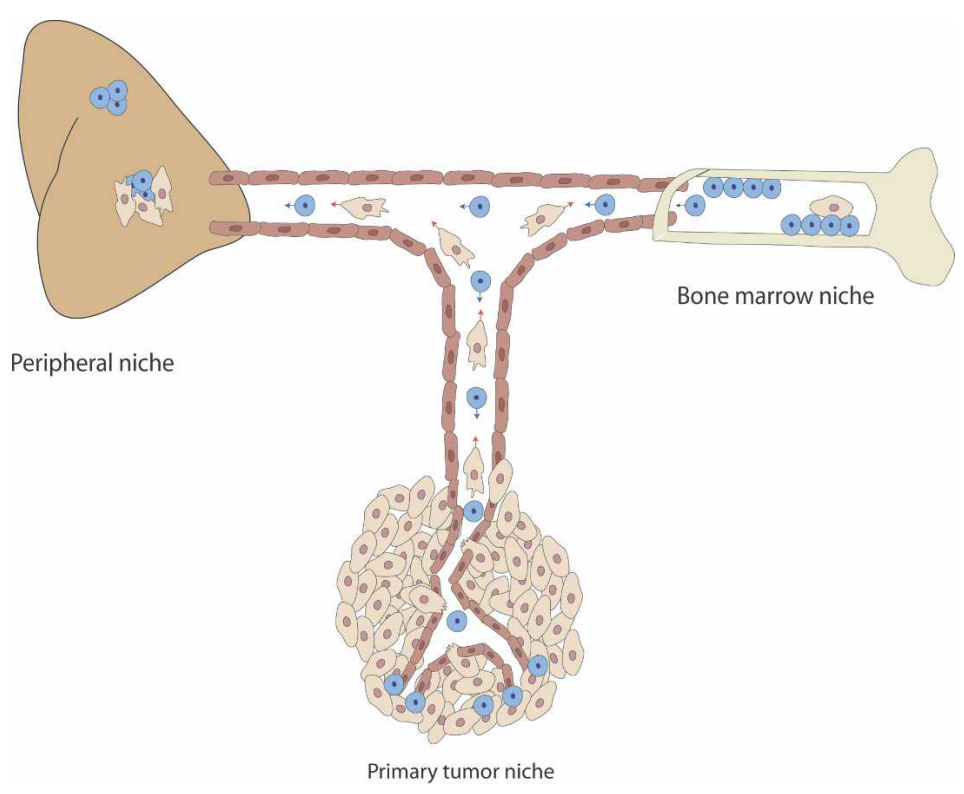


minder et al. 2001; Muller et al. 2001; Sun et al. 2003; Porcile et al. 2004).

Furthermore, neutralization of the SDF-1/CXCR4 axis can block prostate metastasis and growth in osseous sites (Nakamura et al. 2006). Differentiating osteoclasts constitutively produce chemokine CCL22 and may promote bone metastasis of lung cancer cells expressing its receptor CCR4 (Nakamura et al. 2006). Similarly, chemokine CCL12 also mediates site-specific metastatic homing of CCR $7^{+}$breast cancer cell lines (Moore 2001; Muller et al. 2001). Liquid tumors also display site-specific homing to microdomains within marrow, and this may result in dormant "residual" disease and consequent relapse following treatment. High expression of SDF-1 in perivascular microdomains within the BM can mediate highly specific localization patterns of acute lymphoblastic leukemia cells expressing CXCR4 (Sipkins et al. 2005).

In addition to producing large amounts of SDF-1, osteoblasts also express anchorage molecules-including angiopoietin (Ang-1) and osteopontin (Opn)-that contribute to tumor cell recruitment to bone. Opn, often characterized as a cytokine, is a glycophosphoprotein with multiple functions including the ability to stimulate HSC and osteoclast adherence to bone matrix (Asou et al. 2001). At the endosteal surface, Opn is a key molecule in the trans-marrow migration, retention, and negative regulation of HSC cycling within the osteoblastic niche (Nilsson et al. 2005). Recently, substantial data have linked Opn with the regulation of metastatic spread in tumors of the breast, prostate, colon, and liver (Wai and Kuo 2004), and it is consistently found to be highly expressed within metastatic cells and in surrounding tissue stroma (Kang et al. 2003). Induced expression of recombinant Opn confers a migratory and invasive phenotype in human mammary epithelial cells (Tuck et al. 2003).

\section{Far-away fibroblasts: setting the scene}

Fibroblasts at the metastatic site, similar to fibroblasts associated with the primary tumor, appear to provide an environment supportive of tumor cell proliferation (Fig. 1B). Enhanced fibronectin expression and an increase in PDGFR-expressing cells were localized to premetastatic sites early in tumor progression, prior to the arrival of BM-derived HPCs (Kaplan et al. 2005). These findings were likely mediated by tumor-secreted growth factors as similar effects were seen with administration of B16 melanoma-conditioned media. Several studies of hepatic metastasis of B16 melanoma have shown that factors secreted by melanoma cells appear to activate hepatic stellate cells to a myofibroblast-like state associated with SMA expression and cytoskeletal changes (Olaso et al. 1997). Thus, active infiltration of this myofibroblast population is likely induced by melanoma-secreted factors in order to support the growth of incoming tumor cells. Follow-up studies by Olaso et al. (2003) have described a role for these activated hepatic stellate cells in promoting the angiogenic switch of nascent hepatic me- tastases. The infiltration of activated myofibroblasts precedes the recruitment of vascular endothelial cells in the hypoxic avascular metastatic environment. Melanoma signals, as well as hypoxic conditions, were shown to induce VEGF-A production by myofibroblasts, thus promoting angiogenesis and transition to a vascular stage (Olaso et al. 2003). Further evidence supporting the importance of fibroblast motility in cancer metastasis comes from tumor studies in mice lacking the S100A4 gene. S100A4 is a member of the S100 family of small $\mathrm{Ca}^{+}$-binding proteins, many of which have been implicated in cytoskeletal-membrane interactions, calcium signal transduction, and cellular proliferation and differentiation (Heizmann et al. 2002). Fibroblasts lacking S100A4 have impaired motility and invasive properties compared with wild-type fibroblasts (Grum-Schwensen et al. 2005). Furthermore, mice lacking S100A4 have impaired tumor development and do not metastasize. Importantly, coinjection of tumor cells with S100A4 $\left(^{+/+}\right.$ fibroblasts restores metastatic capabilities in mice (Grum-Schwensen et al. 2005). Thus, the ability of fibroblasts to mobilize and actively associate with tumor cells within the metastatic microenvironment is vital for tumor cell survival and progression to full-blown metastases.

A paracrine exchange between tumor cells and distant or local fibroblasts can provide insight into how tumor cells modulate the microenvironment and potentially create systemic changes in distant tissues (Fig. 2). Through the secretion of IL-1, FGF-2, and PDGF, several carcinoma cell lines have been shown to induce HGF secretion from fibroblasts. HGF can then bind to c-Met expressed in many cancer cells and can increase their invasive and migratory capacity (Nakamura et al. 1997). The MMP inhibitor TIMP-1 may also act as a key regulator of HGF/c-Met signaling through suppression of metalloproteinase-10 (ADAM-10) (Kopitz et al. 2007). Other paracrine signals involving TGF- $\beta$, EGF, and insulin growth factor (IGF), as well as Wnt1, likely mediate mutually supportive cross-talk between the stromal cells and tumor cells (Bhowmick et al. 2004).

\section{Hematopoietic progenitors and the premetastatic niche}

According to Paget's theory, the colonization and proliferation of a particular tumor type are dependent on a receptive microenvironment within distant target organs. This idea is currently of direct relevance, as it addresses one of the most intriguing aspects of malignancy; that is, the organ specificity of metastatic progression. The favorable interaction between disseminated tumor cells and the stromal environment is necessary for survival and eventual outgrowth of macrometastases. A poignant question is: Are future metastatic organs intrinsically permissive for tumor growth, or is "conditioning" of these sites dictated by primary tumor burden necessary for metastatic colonization? Although tumor-secreted signals, including chemokines and proteases, have been shown to induce dynamic alterations of the adja- 
cent tumor microenvironment, it is now recognized that systemic changes arise in response to primary tumor growth. An essential role for BM-derived progenitor cells in priming distant tissues for tumor cell implantation and proliferation has recently been revealed (Hiratsuka et al. 2002, 2006; Kaplan et al. 2005). In response to a unique array of chemokines released by the primary tumor, specific cells of hematopoietic origin mobilize from the BM and engraft as cellular clusters into distant organ tissue before the arrival of tumor cells (Fig. 1B). These BMDCs express lineage markers such as VEGFR-1, c-Kit, Sca-1, and CD11b, suggesting an immature status within the tissue parenchyma (Kaplan et al. 2005). Recruitment of VLA-4-expressing BMDCs is associated with the local deposition of fibronectin, providing a highly receptive environment for circulating tumor cells. Inhibiting the incorporation of BMDCs to form the premetastatic sites through antibody administration or depletion of these cells from the BM was sufficient to block metastatic progression (Kaplan et al. 2005). Importantly, tumor-secreted chemokines were able to orchestrate the formation of the premetastatic niche, thus containing the imprints of the tumor cell necessary to dictate the pattern of tumor spread.

Mechanisms promoting the homing of both BMDCs and tumor cells to metastatic sites have come to light recently. Once present within the target tissue, BMDCs appear to interact with and alter the surrounding tissue, in part through the expression of matrix-degrading enzymes such as MMP-9, making a more receptive environment for tumor cell implantation and growth (Hiratsuka et al. 2002; Kaplan et al. 2005). The secretion of hypoxia-induced factors, such as lysyl oxidase, from the primary tumor further promotes metastatic growth at distant sites and may similarly enhance fibronectin production at distant sites prior to tumor cell spread (Kaplan et al. 2005; Erler et al. 2006; Giaccia et al. 2007). In addition, Hiratsuka et al. (2006) have demonstrated that primary tumor cells secrete VEGF-A, TGF- $\beta$, and TNF $\alpha$, which induce the expression of inflammatory chemokines, S100A8 (MRP8/Calgranulin A) and S100A9 (MRP14, Calgranulin B), by both lung epithelium and myeloid cells in distant premetastatic organs (Hiratsuka et al. 2006; Rafii and Lyden 2006). These chemoattractants were shown to increase the mobility of Mac1-expressing myeloid cells in a p38-mediated fashion, thus increasing the infiltration of myeloid cells to premetastatic sites. Similarly, the invasive phenotype of circulating tumor cells appears to be promoted through MAPK p38-mediated pseudopodia formation (Hiratsuka et al. 2006). Thus, S100A8 and S100A9 may be an essential pathway necessary for both myeloid and tumor cell recruitment to future metastatic tissues. Furthermore, BMDCs also express CXCR4, and their interaction with resident fibroblasts can induce localized increase of SDF-1 production, serving as a chemokine gradient and a docking site for $\mathrm{CXCR}^{+}$tumor cells.

Expanding on investigations of the premetastatic niche at distant sites, recent work has demonstrated evidence for the preconditioning of local lymph nodes as a common initial metastatic site for many tumor types. This metastatic site is proposed to act as a gateway to distant metastasis (Hirakawa et al. 2007).

Although the role of EPCs at the metastatic site has not been greatly characterized, there is evidence that this cell type contributes toward the angiogenic stage after metastatic initiation (Fig. 1B). Targeting VEGFR-2 ${ }^{+}$EPCs via administration of VEGFR-2-blocking antibodies results in the formation of small micrometastases without vascularization (Kaplan et al. 2005). In addition, recent studies that inhibit EPC mobilization after metastatic colonization, via knockdown of Id1, report angiogenesis inhibition and impaired macrometastasis formation (Gao et al. 2008; Rafii and Lyden 2008). Such reports support the idea that recruitment of EPCs is necessary for vessel formation and maturation to a fully developed metastatic lesion.

\section{Perspective: the niche as an immature privileged refuge}

BM-derived hematopoietic progenitor and immature myeloid cells $\left(\mathrm{CD} 11 \mathrm{~b}^{+} \mathrm{GR}-1^{+}\right)$contribute to neo-angiogenesis within the primary tumor and have been found to promote lymphangiogenesis and metastatic spread in their strategic location at the invasive edge of the tumor (Lyden et al. 2001; Yang et al. 2004). Given the association of immature hematopoietic cell types with enhanced tumor progression and metastasis, it is possible that tumor cells secrete factors that maintain an immature state as a means to promote immune invasion. Immature myeloid cells can suppress differentiation of mature tumor antigen-presenting dendritic cells evading the host adaptive immune response (Lin et al. 2002). These data suggest a biological selection for promoting an immature phenotype, resulting in immune dysfunction and diminished surveillance in response to tumor cells.

The premetastatic niche, similar to the hematopoietic stem cell niche within the BM, may also create a microenvironment preventing differentiation of tumor cells. A niche can alter the cells within its space. Therefore, tumor cells that localize to these sites may be more apt to grow and survive similar to normal stem cell niche dynamics, where niche occupancy confers a survival advantage to cells. Moreover, these tumor cells may be altered by this specialized microenvironment and gain stem-like properties. Such characteristics may promote further tumor recruitment and immune evasion. Tumor cell occupation of such a site might, in turn, have a reciprocal role within the microenvironment, altering its conditions to further promote pathology. In an altered microenvironment, a so-called pathological niche, cells can obtain new genetic alterations and acquire new functions leading to tumor promotion, progression, and metastatic niche formation. The migration of cells from niche to niche may result in transmission of this deregulation, and such cell dynamics may be central to targeting this process in order to prevent metastatic spread. Cancer stem cells or pathological niches, like physiologi- 
cal stem cells and their niches, may maintain cells in a quiescent state and minimize cell division, and can therefore evade traditional anti-mitotic chemotherapy or radiotherapy that target cells with a high turnover. For example, as has been shown in gliomas, cancer stem cells are resistant to radiotherapy due to an increased capacity for DNA repair (Liu et al. 2006). This finding may be a result of reciprocal alterations in tumor cells and their pathological microenvironment.

\section{Potential therapeutic implications}

Scientific advances in the understanding of metastasis are opening up a new area of cancer therapeutics. In order for anti-metastatic therapy to be successful, several key concepts must be incorporated. The cells that mediate the mobile nature of tumor progression are crucial for targeting these early and fundamental events. Inhibition of metastasis requires targeting of both the metastasizing cell and its supportive microenvironment. Recognition that the preparatory changes in the premetastatic microenvironment occur very early in tumorigenesis suggests that anti-metastatic agents must be used together with the primary therapy. Furthermore, therapy that focuses on the dynamic nature of tumors and their supportive cells may be critical to preventing tumor progression. Therefore, a strategy that manipulates the migrating BMDCs themselves, as well as their signaling pathways, might prove quite successful. The BMDCs that home to the tumor neovasculature and premetastatic sites could be used as "magic bullets," delivery vehicles for anti-cancer strategies (Arafat et al. 2000). The feasibility of integrating a suicide gene into BMderived progenitors to reduce tumor size and vascularity has already been confirmed in several animal studies (Komarova et al. 2006; Lotem and Sachs 2006). Not only HPCs and EPCs, but also fibroblasts and stromal progenitors that migrate to tumor sites might prove particularly useful as carriers of oncolytic adenoviruses or as direct targets of "activated" or genetically altered stromal cells.

Alternatively, targeting the homing mechanisms by which cancer stem cells migrate to metastatic sites or the factors that govern the cellular dynamics within these "pathological niches" may be feasible. Identifying and inhibiting those cytokines or growth factors, which promote cellular migration, as recently demonstrated with antibodies to PlGF (Fischer et al. 2007), may provide an additional arsenal for abrogation of these early and evolving processes of tumor spread. Characterization of cancer stem cells and their "pathological niches" in solid malignancies may reveal potential therapeutic targets to inhibit metastasis.

\section{Conclusion}

Although often a late presentation of carcinogenesis, the metastatic process need not be a final event. The basic tenets of metastasis as a late event may be, in fact, over- turned as the evolution of a malignancy is elucidated. Through a series of small steps leading to subtle changes in distant tissues, metastasis likely has an early initiation that reflects its true systemic nature. Unraveling the details of these subtle systemic changes that commence with malignant transformation may lead to a paradigm shift in the design of therapies and has implications in how host stromal and immune response mediates the development of carcinogenesis as well. Longstanding players in metastatic growth have been neglected in order to focus on the precise detailing of the migrating cancer cell and the genetic alterations allowing for its dissemination. However, new evidence is emerging on how supporting cells composing the tumor microenvironment promote disease progression and metastasis. The underlying mechanisms of how a tumor cell alters its local and distant microenvironment are also receiving more attention. Dissecting these individual pieces will provide valuable insights and direct future investigations. The ecology of a metastatic tumor includes genetically altered tumor cells and their heterotypic interactions with nonmalignant cells and their stromal support structure. Focus on the dynamic exchange of cells from local and distant environments, to the invasive front of the tumor, to the premetastatic and metastatic niches can provide novel strategies for successfully targeting these processes.

\section{Acknowledgments}

This work was supported by NCI R01CA098234 (to D.L.), the Emerald Foundation (to D.L.), the Nancy C. and Daniel P. Paduano Fund (to D.L.), the Charles and Meryl Witmer Family Foundation (to D.L.), the Malcolm Hewitt Wiener Foundation (to D.L.), National Foundation for Cancer Research (to D.L.), AHEFA Foundation (to D.L. and R.K.), the Doris Duke Charitable Foundation (to R.K.), Hope Street Kids Foundation (to R.K.), Charles, Lillian and Betty Neuwirth Scholar Program (to R.K.), the Butler Foundation (to R.K.), Association for Research of Childhood Cancer (to R.K.), the American Society of Clinical Oncology (to R.K.), the Childern's Cancer and Blood Foundation (to J.W., R.K., and D.L.), Howard Hughes Medical Institution (to S.R.), and the National Heart, Lung, and Blood Institution (to S.R.).

\section{References}

Abramsson, A., Lindblom, P., and Betsholtz, C. 2003. Endothelial and nonendothelial sources of PDGF-B regulate pericyte recruitment and influence vascular pattern formation in tumors. J. Clin. Invest. 112: 1142-1151.

Ara, T., Tokoyoda, K., Sugiyama, T., Egawa, T., Kawabata, K., and Nagasawa, T. 2003. Long-term hematopoietic stem cells require stromal cell-derived factor-1 for colonizing bone marrow during ontogeny. Immunity 19: 257-267.

Arafat, W.O., Casado, E., Wang, M., Alvarez, R.D., Siegal, G.P., Glorioso, J.C., Curiel, D.T., and Gomez-Navarro, J. 2000. Genetically modified $\mathrm{CD} 34^{+}$cells exert a cytotoxic bystander effect on human endothelial and cancer cells. Clin. Cancer Res. 6: 4442-4448.

Asou, Y., Rittling, S.R., Yoshitake, H., Tsuji, K., Shinomiya, K., Nifuji, A., Denhardt, D.T., and Noda, M. 2001. Osteopontin 
facilitates angiogenesis, accumulation of osteoclasts, and resorption in ectopic bone. Endocrinology 142: 1325-1332.

Atula, S., Grenman, R., and Syrjanen, S. 1997. Fibroblasts can modulate the phenotype of malignant epithelial cells in vitro. Exp. Cell Res. 235: 180-187.

Azenshtein, E., Luboshits, G., Shina, S., Neumark, E., Shahbazian, D., Weil, M., Wigler, N., Keydar, I., and Ben-Baruch, A. 2002. The CC chemokine RANTES in breast carcinoma progression: Regulation of expression and potential mechanisms of promalignant activity. Cancer Res. 62: 1093-1102.

Baluk, P., Hashizume, H., and McDonald, D.M. 2005. Cellular abnormalities of blood vessels as targets in cancer. Curr. Opin. Genet. Dev. 15: 102-111.

Barcellos-Hoff, M.H. 1998. The potential influence of radiationinduced microenvironments in neoplastic progression. $J$. Mammary Gland Biol. Neoplasia 3: 165-175.

Barcellos-Hoff, M.H. and Ravani, S.A. 2000. Irradiated mammary gland stroma promotes the expression of tumorigenic potential by unirradiated epithelial cells. Cancer Res. 60: 1254-1260.

Barleon, B., Sozzani, S., Zhou, D., Weich, H.A., Mantovani, A., and Marme, D. 1996. Migration of human monocytes in response to vascular endothelial growth factor (VEGF) is mediated via the VEGF receptor flt-1. Blood 87: 3336-3343.

Bergers, G., Song, S., Meyer-Morse, N., Bergsland, E., and Hanahan, D. 2003. Benefits of targeting both pericytes and endothelial cells in the tumor vasculature with kinase inhibitors. I. Clin. Invest. 111: 1287-1295.

Bhowmick, N.A., Neilson, E.G., and Moses, H.L. 2004. Stromal fibroblasts in cancer initiation and progression. Nature 432: 332-337.

Bissell, M.J. and Radisky, D. 2001. Putting tumours in context. Nat. Rev. Cancer 1: 46-54.

Boire, A., Covic, L., Agarwal, A., Jacques, S., Sherifi, S., and Kuliopulos, A. 2005. PAR1 is a matrix metalloprotease-1 receptor that promotes invasion and tumorigenesis of breast cancer cells. Cell 120: 303-313.

Brandt, B., Junker, R., Griwatz, C., Heidl, S., Brinkmann, O., Semjonow, A., Assmann, G., and Zanker, K.S. 1996. Isolation of prostate-derived single cells and cell clusters from human peripheral blood. Cancer Res. 56: 4556-4561.

Bronte, V., Chappell, D.B., Apolloni, E., Cabrelle, A., Wang, M., Hwu, P., and Restifo, N.P. 1999. Unopposed production of granulocyte-macrophage colony-stimulating factor by tumors inhibits $\mathrm{CD}^{+} \mathrm{T}$ cell responses by dysregulating antigen-presenting cell maturation. J. Immunol. 162: 5728-5737.

Camps, J.L., Chang, S.M., Hsu, T.C., Freeman, M.R., Hong, S.J., Zhau, H.E., von Eschenbach, A.C., and Chung, L.W. 1990. Fibroblast-mediated acceleration of human epithelial tumor growth in vivo. Proc. Nat1. Acad. Sci. 87: 75-79.

Carr, I. 1983. Experimental lymphatic metastasis. J. Microsc. 131: $211-220$

Case, J., Mead, L.E., Bessler, W.K., Prater, D., White, H.A., Saadatzadeh, M.R., Bhavsar, J.R., Yoder, M.C., Haneline, L.S., and Ingram, D.A. 2007. Human CD $34^{+} \mathrm{C} 133^{+}$VEGFR-2 ${ }^{+}$cells are not endothelial progenitor cells but distinct, primitive hematopoietic progenitors. Exp. Hematol. 35: 1109-1118.

Castellani, P., Borsi, L., Carnemolla, B., Biro, A., Dorcaratto, A., Viale, G.L., Neri, D., and Zardi, L. 2002. Differentiation between high- and low-grade astrocytoma using a human recombinant antibody to the extra domain-B of fibronectin. Am. J. Pathol. 161: 1695-1700.

Condeelis, J. and Segall, J.E. 2003. Intravital imaging of cell movement in tumours. Nat. Rev. Cancer 3: 921-930.

Cross, A.K. and Woodroofe, M.N. 1999. Chemokine modulation of matrix metalloproteinase and TIMP production in adult rat brain microglia and a human microglial cell line in vitro. Glia 28: 183-189.

Dar, A., Goichberg, P., Shinder, V., Kalinkovich, A., Kollet, O., Netzer, N., Margalit, R., Zsak, M., Nagler, A., Hardan, I., et al. 2005. Chemokine receptor CXCR4-dependent internalization and resecretion of functional chemokine SDF-1 by bone marrow endothelial and stromal cells. Nat. Immunol. 6: $1038-1046$.

De Palma, M., Venneri, M.A., Galli, R., Sergi Sergi, L., Politi, L.S., Sampaolesi, M., and Naldini, L. 2005. Tie2 identifies a hematopoietic lineage of proangiogenic monocytes required for tumor vessel formation and a mesenchymal population of pericyte progenitors. Cancer Cell 8: 211-226.

Direkze, N.C., Hodivala-Dilke, K., Jeffery, R., Hunt, T., Poulsom, R., Oukrif, D., Alison, M.R., and Wright, N.A. 2004. Bone marrow contribution to tumor-associated myofibroblasts and fibroblasts. Cancer Res. 64: 8492-8495.

Donovan, M.J., Lin, M.I., Wiegn, P., Ringstedt, T., Kraemer, R., Hahn, R., Wang, S., Ibanez, C.F., Rafii, S., and Hempstead, B.L. 2000. Brain derived neurotrophic factor is an endothelial cell survival factor required for intramyocardial vessel stabilization. Development 127: 4531-4540.

Erler, J.T., Bennewith, K.L., Nicolau, M., Dornhofer, N., Kong, C., Le, Q.T., Chi, J.T., Jeffrey, S.S., and Giaccia, A.J. 2006. Lysyl oxidase is essential for hypoxia-induced metastasis. Nature 440: 1222-1226.

Farber, E. 1984. The multistep nature of cancer development. Cancer Res. 44: 4217-4223.

Fischer, C., Jonckx, B., Mazzone, M., Zacchigna, S., Loges, S., Pattarini, L., Chorianopoulos, E., Liesenborghs, L., Koch, M., De Mol, M., et al. 2007. Anti-PlGF inhibits growth of VEGF(R)-inhibitor-resistant tumors without affecting healthy vessels. Cell 131: 463-475.

Friedl, P. and Brocker, E.B. 2000. The biology of cell locomotion within three-dimensional extracellular matrix. Cell. Mol. Life Sci. 57: 41-64.

Friedl, P., Noble, P.B., Walton, P.A., Laird, D.W., Chauvin, P.J., Tabah, R.J., Black, M., and Zanker, K.S. 1995. Migration of coordinated cell clusters in mesenchymal and epithelial cancer explants in vitro. Cancer Res. 55: 4557-4560.

Fukumura, D., Xavier, R., Sugiura, T., Chen, Y., Park, E.C., Lu, N., Selig, M., Nielsen, G., Taksir, T., Jain, R.K., et al. 1998. Tumor induction of VEGF promotor activity in stromal cells. Cell 94: 715-725.

Gaggioli, C., Hooper, S., Hidalgo-Carcedo, C., Grosse, R., Marshall, J.F., Harrington, K., and Sahai, E. 2007. Fibroblast-led collective invasion of carcinoma cells with differing roles for RhoGTPases in leading and following cells. Nat. Cell Biol. 9: 1392-1400.

Gao, D., Nolan, D.J., Mellick, A.S., Bambino, K., McDonnell, K., and Mittal, V. 2008. Endothelial progenitor cells control the angiogenic switch in mouse lung metastasis. Science 319: 195-198

Geminder, H., Sagi-Assif, O., Goldberg, L., Meshel, T., Rechavi, G., Witz, I.P., and Ben-Baruch, A. 2001. A possible role for CXCR4 and its ligand, the CXC chemokine stromal cellderived factor-1, in the development of bone marrow metastases in neuroblastoma. J. Immunol. 167: 4747-4757.

Giaccia, A.J., Erler, J.T., Bennewith, K.L., Le, Q.T., and Koong, A. 2007. Lysyl oxidase, hypoxia and the pre-metastatic niche. Pigment Cell Res. 20: 513-580.

Gleave, M., Hsieh, J.T., Gao, C.A., von Eschenbach, A.C., and Chung, L.W. 1991. Acceleration of human prostate cancer growth in vivo by factors produced by prostate and bone fibroblasts. Cancer Res. 51: 3753-3761.

Goswami, S., Sahai, E., Wyckoff, J.B., Cammer, M., Cox, D., 
Pixley, F.J., Stanley, E.R., Segall, J.E., and Condeelis, J.S. 2005. Macrophages promote the invasion of breast carcinoma cells via a colony-stimulating factor-1/epidermal growth factor paracrine loop. Cancer Res. 65: 5278-5283.

Gothert, J.R., Gustin, S.E., van Eekelen, J.A., Schmidt, U., Hall, M.A., Jane, S.M., Green, A.R., Gottgens, B., Izon, D.J., and Begley, C.G. 2004. Genetically tagging endothelial cells in vivo: Bone marrow-derived cells do not contribute to tumor endothelium. Blood 104: 1769-1777.

Grum-Schwensen, B., Klingelhofer, J., Berg, C.H., El-Naaman, C., Grigorian, M., Lukanidin, E., and Ambartsumian, N. 2005. Suppression of tumor development and metastasis formation in mice lacking the S100A4(mts1) gene. Cancer Res. 65: 3772-3780.

Grunewald, M., Avraham, I., Dor, Y., Bachar-Lustig, E., Itin, A., Jung, S., Chimenti, S., Landsman, L., Abramovitch, R., and Keshet, E. 2006. VEGF-induced adult neovascularization: Recruitment, retention, and role of accessory cells. Cell 124: 175-189.

Hall, B., Andreeff, M., and Marini, F. 2007. The participation of mesenchymal stem cells in tumor stroma formation and their application as targeted-gene delivery vehicles. Handb. Exp. Pharmacol. 180: 263-283.

Hanahan, D. and Folkman, J. 1996. Patterns and emerging mechanisms of the angiogenic switch during tumorigenesis. Cell 86: 353-364.

Hanahan, D. and Weinberg, R.A. 2000. The hallmarks of cancer. Cell 100: 57-70.

Harrell, M.I., Iritani, B.M., and Ruddell, A. 2007. Tumor-induced sentinel lymph node lymphangiogenesis and increased lymph flow precede melanoma metastasis. Am. I. Pathol. 170: 774-786.

Hayward, S.W., Wang, Y., Cao, M., Hom, Y.K., Zhang, B., Grossfeld, G.D., Sudilovsky, D., and Cunha, G.R. 2001. Malignant transformation in a nontumorigenic human prostatic epithelial cell line. Cancer Res. 61: 8135-8142.

He, Y., Rajantie, I., Ilmonen, M., Makinen, T., Karkkainen, M.J., Haiko, P., Salven, P., and Alitalo, K. 2004. Preexisting lymphatic endothelium but not endothelial progenitor cells are essential for tumor lymphangiogenesis and lymphatic metastasis. Cancer Res. 64: 3737-3740.

Heizmann, C.W., Fritz, G., and Schafer, B.W. 2002. S100 proteins: Structure, functions and pathology. Front. Biosci. 7: D1356-D1368.

Heppner, K.J., Matrisian, L.M., Jensen, R.A., and Rodgers, W.H. 1996. Expression of most matrix metalloproteinase family members in breast cancer represents a tumor-induced host response. Am. J. Pathol. 149: 273-282.

Hildenbrand, R., Dilger, I., Horlin, A., and Stutte, H.J. 1995. Urokinase and macrophages in tumour angiogenesis. Br. J. Cancer 72: 818-823.

Hirakawa, S., Kodama, S., Kunstfeld, R., Kajiya, K., Brown, L.F., and Detmar, M. 2005. VEGF-A induces tumor and sentinel lymph node lymphangiogenesis and promotes lymphatic metastasis. J. Exp. Med. 201: 1089-1099.

Hirakawa, S., Brown, L.F., Kodama, S., Paavonen, K., Alitalo, K., and Detmar, M. 2007. VEGF-C-induced lymphangiogenesis in sentinel lymph nodes promotes tumor metastasis to distant sites. Blood 109: 1010-1017.

Hiratsuka, S., Nakamura, K., Iwai, S., Murakami, M., Itoh, T., Kijima, H., Shipley, J.M., Senior, R.M., and Shibuya, M. 2002. MMP9 induction by vascular endothelial growth factor receptor-1 is involved in lung-specific metastasis. Cancer Cell 2: 289-300.

Hiratsuka, S., Watanabe, A., Aburatani, H., and Maru, Y. 2006. Tumour-mediated upregulation of chemoattractants and re- cruitment of myeloid cells predetermines lung metastasis. Nat. Cell Biol. 8: 1369-1375.

Hudson, J.D., Shoaibi, M.A., Maestro, R., Carnero, A., Hannon, G.J., and Beach, D.H. 1999. A proinflammatory cytokine inhibits p53 tumor suppressor activity. J. Exp. Med. 190: 13751382.

Ishii, G., Sangai, T., Oda, T., Aoyagi, Y., Hasebe, T., Kanomata, N., Endoh, Y., Okumura, C., Okuhara, Y., Magae, J., et al. 2003. Bone-marrow-derived myofibroblasts contribute to the cancer-induced stromal reaction. Biochem. Biophys. Res. Commun. 309: 232-240.

Jain, R.K. and Booth, M.F. 2003. What brings pericytes to tumor vessels? J. Clin. Invest. 112: 1134-1136.

Jin, D.K., Shido, K., Kopp, H.G., Petit, I., Shmelkov, S.V., Young, L.M., Hooper, A.T., Amano, H., Avecilla, S.T., Heissig, B., et al. 2006. Cytokine-mediated deployment of SDF-1 induces revascularization through recruitment of CXCR4 ${ }^{+}$hemangiocytes. Nat. Med. 12: 557-567.

Kaifi, J.T., Yekebas, E.F., Schurr, P., Obonyo, D., Wachowiak, R., Busch, P., Heinecke, A., Pantel, K., and Izbicki, J.R. 2005. Tumor-cell homing to lymph nodes and bone marrow and CXCR4 expression in esophageal cancer. I. Natl. Cancer Inst. 97: 1840-1847.

Kalluri, R. and Zeisberg, M. 2006. Fibroblasts in cancer. Nat. Rev. Cancer 6: 392-401.

Kang, Y., Siegel, P.M., Shu, W., Drobnjak, M., Kakonen, S.M., Cordon-Cardo, C., Guise, T.A., and Massague, J. 2003. A multigenic program mediating breast cancer metastasis to bone. Cancer Cell 3: 537-549.

Kaplan, R.N., Riba, R.D., Zacharoulis, S., Bramley, A.H., Vincent, L., Costa, C., MacDonald, D.D., Jin, D.K., Shido, K., Kerns, S.A., et al. 2005. VEGFR1-positive haematopoietic bone marrow progenitors initiate the pre-metastatic niche. Nature 438: 820-827.

Karnoub, A.E., Dash, A.B., Vo, A.P., Sullivan, A., Brooks, M.W., Bell, G.W., Richardson, A.L., Polyak, K., Tubo, R., and Weinberg, R.A. 2007. Mesenchymal stem cells within tumour stroma promote breast cancer metastasis. Nature 449: 557563.

Katz, M., Amit, I., Citri, A., Shay, T., Carvalho, S., Lavi, S., Milanezi, F., Lyass, L., Amariglio, N., Jacob-Hirsch, J., et al. 2007. A reciprocal tensin-3-cten switch mediates EGFdriven mammary cell migration. Nat. Cell Biol. 9: 961-969.

Kelly, P.M., Davison, R.S., Bliss, E., and McGee, J.O. 1988. Macrophages in human breast disease: A quantitative immunohistochemical study. Br. J. Cancer 57: 174-177.

Komarova, S., Kawakami, Y., Stoff-Khalili, M.A., Curiel, D.T., and Pereboeva, L. 2006. Mesenchymal progenitor cells as cellular vehicles for delivery of oncolytic adenoviruses. Mol. Cancer Ther. 5: 755-766.

Kopitz, C., Gerg, M., Bandapalli, O.R., Ister, D., Pennington, C.J., Hauser, S., Flechsig, C., Krell, H.W., Antolovic, D., Brew, K., et al. 2007. Tissue inhibitor of metalloproteinases-1 promotes liver metastasis by induction of hepatocyte growth factor signaling. Cancer Res. 67: 8615-8623.

Kopp, H.G. and Rafii, S. 2007. Thrombopoietic cells and the bone marrow vascular niche. Ann. N. Y. Acad. Sci. 1106: 175-179.

Kopp, H.G., Ramos, C.A., and Rafii, S. 2006. Contribution of endothelial progenitors and proangiogenic hematopoietic cells to vascularization of tumor and ischemic tissue. Curr. Opin. Hematol. 13: 175-181.

Kusmartsev, S. and Gabrilovich, D.I. 2006. Role of immature myeloid cells in mechanisms of immune evasion in cancer. Cancer Immunol. Immunother. 55: 237-245.

Kusmartsev, S., Nefedova, Y., Yoder, D., and Gabrilovich, D.I. 
2004. Antigen-specific inhibition of $\mathrm{CD}^{+} \mathrm{T}$ cell response by immature myeloid cells in cancer is mediated by reactive oxygen species. J. Immunol. 172: 989-999.

Kusmartsev, S., Nagaraj, S., and Gabrilovich, D.I. 2005. Tumorassociated $\mathrm{CD}^{+} \mathrm{T}$ cell tolerance induced by bone marrowderived immature myeloid cells. I. Immunol. 175: 45834592.

Lamalice, L., Le Boeuf, F., and Huot, J. 2007. Endothelial cell migration during angiogenesis. Circ. Res. 100: 782-794.

Lebret, S.C., Newgreen, D.F., Thompson, E.W., and Ackland, M.L. 2007. Induction of epithelial to mesenchymal transition in PMC42-LA human breast carcinoma cells by carcinoma-associated fibroblast secreted factors. Breast Cancer Res. 9: R19. doi: 10.1186/bcr1656.

Leek, R.D., Harris, A.L., and Lewis, C.E. 1994. Cytokine networks in solid human tumors: Regulation of angiogenesis. $J$ Leukoc. Biol. 56: 423-435.

Leek, R.D., Hunt, N.C., Landers, R.J., Lewis, C.E., Royds, J.A., and Harris, A.L. 2000. Macrophage infiltration is associated with VEGF and EGFR expression in breast cancer. J. Pathol. 190: $430-436$.

Lewis, J.S., Landers, R.J., Underwood, J.C., Harris, A.L., and Lewis, C.E. 2000. Expression of vascular endothelial growth factor by macrophages is up-regulated in poorly vascularized areas of breast carcinomas. J. Pathol. 192: 150-158.

Li, J.J., Huang, Y.Q., Basch, R., and Karpatkin, S. 2001. Thrombin induces the release of angiopoietin-1 from platelets. Thromb. Haemost. 85: 204-206.

Li, B., Sharpe, E.E., Maupin, A.B., Teleron, A.A., Pyle, A.L., Carmeliet, P., and Young, P.P. 2006. VEGF and PlGF promote adult vasculogenesis by enhancing EPC recruitment and vessel formation at the site of tumor neovascularization. FASEB I. 20: 1495-1497.

Lin, E.Y., Nguyen, A.V., Russell, R.G., and Pollard, J.W. 2001. Colony-stimulating factor 1 promotes progression of mammary tumors to malignancy. J. Exp. Med. 193: 727-740.

Lin, E.Y., Gouon-Evans, V., Nguyen, A.V., and Pollard, J.W. 2002. The macrophage growth factor CSF-1 in mammary gland development and tumor progression. J. Mammary Gland Biol. Neoplasia 7: 147-162.

Lin, E.Y., Jones, J.G., Li, P., Zhu, L., Whitney, K.D., Muller, W.J., and Pollard, J.W. 2003. Progression to malignancy in the polyoma middle $\mathrm{T}$ oncoprotein mouse breast cancer model provides a reliable model for human diseases. Am. J. Pathol. 163: 2113-2126.

Lin, E.Y., Li, J.F., Gnatovskiy, L., Deng, Y., Zhu, L., Grzesik, D.A., Qian, H., Xue, X.N., and Pollard, J.W. 2006. Macrophages regulate the angiogenic switch in a mouse model of breast cancer. Cancer Res. 66: 11238-11246.

Liotta, L.A., Saidel, M.G., and Kleinerman, J. 1976. The significance of hematogenous tumor cell clumps in the metastatic process. Cancer Res. 36: 889-894.

Liu, G., Yuan, X., Zeng, Z., Tunici, P., Ng, H., Abdulkadir, I.R., Lu, L., Irvin, D., Black, K.L., and Yu, J.S. 2006. Analysis of gene expression and chemoresistance of $\mathrm{CD}_{133^{+}}$cancer stem cells in glioblastoma. Mol. Cancer 5: 67. doi: 10.1186/ 1476-4598-5-67.

Locati, M., Deuschle, U., Massardi, M.L., Martinez, F.O., Sironi, M., Sozzani, S., Bartfai, T., and Mantovani, A. 2002. Analysis of the gene expression profile activated by the CC chemokine ligand 5/RANTES and by lipopolysaccharide in human monocytes. J. Immunol. 168: 3557-3562.

Lochter, A., Galosy, S., Muschler, J., Freedman, N., Werb, Z., and Bissell, M.J. 1997. Matrix metalloproteinase stromelysin-1 triggers a cascade of molecular alterations that leads to stable epithelial-to-mesenchymal conversion and a prema- lignant phenotype in mammary epithelial cells. J. Cell Biol. 139: $1861-1872$.

Lotem, J. and Sachs, L. 2006. Epigenetics and the plasticity of differentiation in normal and cancer stem cells. Oncogene 25: 7663-7672.

Lyden, D., Young, A.Z., Zagzag, D., Yan, W., Gerald, W., O'Reilly, R., Bader, B.L., Hynes, R.O., Zhuang, Y., Manova, K., et al. 1999. Id 1 and Id 3 are required for neurogenesis, angiogenesis and vascularization of tumour xenografts. $\mathrm{Na}$ ture 401: 670-677.

Lyden, D., Hattori, K., Dias, S., Costa, C., Blaikie, P., Butros, L., Chadburn, A., Heissig, B., Marks, W., Witte, L., et al. 2001. Impaired recruitment of bone-marrow-derived endothelial and hematopoietic precursor cells blocks tumor angiogenesis and growth. Nat. Med. 7: 1194-1201.

Maeda, H. and Akaike, T. 1998. Nitric oxide and oxygen radicals in infection, inflammation, and cancer. Biochemistry (Mosc.) 63: 854-865.

Mantovani, A., Sozzani, S., Locati, M., Allavena, P., and Sica, A. 2002. Macrophage polarization: Tumor-associated macrophages as a paradigm for polarized M2 mononuclear phagocytes. Trends Immunol. 23: 549-555.

Massberg, S., Konrad, I., Schurzinger, K., Lorenz, M., Schneider, S., Zohlnhoefer, D., Hoppe, K., Schiemann, M., Kennerknecht, E., Sauer, S., et al. 2006. Platelets secrete stromal cell-derived factor $1 \alpha$ and recruit bone marrow-derived progenitor cells to arterial thrombi in vivo. J. Exp. Med. 203: 1221-1233.

Melani, C., Chiodoni, C., Forni, G., and Colombo, M.P. 2003. Myeloid cell expansion elicited by the progression of spontaneous mammary carcinomas in c-erbB-2 transgenic BALB/c mice suppresses immune reactivity. Blood 102: 2138-2145.

Mhawech, P., Dulguerov, P., Assaly, M., Ares, C., and Allal, A.S. 2005. EB-D fibronectin expression in squamous cell carcinoma of the head and neck. Oral Oncol. 41: 82-88.

Midulla, M., Verma, R., Pignatelli, M., Ritter, M.A., CourtenayLuck, N.S., and George, A.J. 2000. Source of oncofetal EDB-containing fibronectin: Implications of production by both tumor and endothelial cells. Cancer Res. 60: 164-169.

Mohle, R., Green, D., Moore, M.A., Nachman, R.L., and Rafii, S. 1997. Constitutive production and thrombin-induced release of vascular endothelial growth factor by human megakaryocytes and platelets. Proc. Nat1. Acad. Sci. 94: 663-668.

Moore, M.A. 2001. The role of chemoattraction in cancer metastases. Bioessays 23: 674-676.

Mueller, M.M. and Fusenig, N.E. 2004. Friends or foes-Bipolar effects of the tumour stroma in cancer. Nat. Rev. Cancer 4: 839-849.

Muller, A., Homey, B., Soto, H., Ge, N., Catron, D., Buchanan, M.E., McClanahan, T., Murphy, E., Yuan, W., Wagner, S.N., et al. 2001. Involvement of chemokine receptors in breast cancer metastasis. Nature 410: 50-56.

Muller, T., Bain, G., Wang, X., and Papkoff, J. 2002. Regulation of epithelial cell migration and tumor formation by $\beta$-catenin signaling. Exp. Cell Res. 280: 119-133.

Murdoch, C., Giannoudis, A., and Lewis, C.E. 2004. Mechanisms regulating the recruitment of macrophages into hypoxic areas of tumors and other ischemic tissues. Blood 104: 2224-2234.

Nagasawa, T., Hirota, S., Tachibana, K., Takakura, N., Nishikawa, S., Kitamura, Y., Yoshida, N., Kikutani, H., and Kishimoto, T. 1996. Defects of B-cell lymphopoiesis and bonemarrow myelopoiesis in mice lacking the CXC chemokine PBSF/SDF-1. Nature 382: 635-638.

Nakamura, T., Matsumoto, K., Kiritoshi, A., Tano, Y., and Na- 
kamura, T. 1997. Induction of hepatocyte growth factor in fibroblasts by tumor-derived factors affects invasive growth of tumor cells: In vitro analysis of tumor-stromal interactions. Cancer Res. 57: 3305-3313.

Nakamura, E.S., Koizumi, K., Kobayashi, M., Saitoh, Y., Arita, Y., Nakayama, T., Sakurai, H., Yoshie, O., and Saiki, I. 2006. RANKL-induced CCL22/macrophage-derived chemokine produced from osteoclasts potentially promotes the bone metastasis of lung cancer expressing its receptor CCR4. Clin. Exp. Metastasis 23: 9-18.

Nakao, S., Kuwano, T., Tsutsumi-Miyahara, C., Ueda, S., Kimura, Y.N., Hamano, S., Sonoda, K.H., Saijo, Y., Nukiwa, T., Strieter, R.M., et al. 2005. Infiltration of COX-2-expressing macrophages is a prerequisite for IL- $1 \beta$-induced neovascularization and tumor growth. I. Clin. Invest. 115: 29792991.

Nilsson, S.K., Johnston, H.M., Whitty, G.A., Williams, B., Webb, R.J., Denhardt, D.T., Bertoncello, I., Bendall, L.J., Simmons, P.J., and Haylock, D.N. 2005. Osteopontin, a key component of the hematopoietic stem cell niche and regulator of primitive hematopoietic progenitor cells. Blood 106: 12321239.

Nolan, D.J., Ciarrocchi, A., Mellick, A.S., Jaggi, J.S., Bambino, K., Gupta, S., Heikamp, E., McDevitt, M.R., Scheinberg, D.A., Benezra, R., et al. 2007. Bone marrow-derived endothelial progenitor cells are a major determinant of nascent tumor neovascularization. Genes \& Dev. 21: 1546-1558.

Ohuchida, K., Mizumoto, K., Murakami, M., Qian, L.W., Sato, N., Nagai, E., Matsumoto, K., Nakamura, T., and Tanaka, M. 2004. Radiation to stromal fibroblasts increases invasiveness of pancreatic cancer cells through tumor-stromal interactions. Cancer Res. 64: 3215-3222.

Okada, A., Bellocq, J.P., Rouyer, N., Chenard, M.P., Rio, M.C., Chambon, P., and Basset, P. 1995. Membrane-type matrix metalloproteinase (MT-MMP) gene is expressed in stromal cells of human colon, breast, and head and neck carcinomas. Proc. Natl. Acad. Sci. 92: 2730-2734.

Okamoto, R., Ueno, M., Yamada, Y., Takahashi, N., Sano, H., Suda, T., and Takakura, N. 2005. Hematopoietic cells regulate the angiogenic switch during tumorigenesis. Blood 105: 2757-2763.

Olaso, E., Santisteban, A., Bidaurrazaga, J., Gressner, A.M., Rosenbaum, J., and Vidal-Vanaclocha, F. 1997. Tumor-dependent activation of rodent hepatic stellate cells during experimental melanoma metastasis. Hepatology 26: 634-642.

Olaso, E., Salado, C., Egilegor, E., Gutierrez, V., Santisteban, A., Sancho-Bru, P., Friedman, S.L., and Vidal-Vanaclocha, F. 2003. Proangiogenic role of tumor-activated hepatic stellate cells in experimental melanoma metastasis. Hepatology 37: 674-685.

Olumi, A.F., Grossfeld, G.D., Hayward, S.W., Carroll, P.R., Tlsty, T.D., and Cunha, G.R. 1999. Carcinoma-associated fibroblasts direct tumor progression of initiated human prostatic epithelium. Cancer Res. 59: 5002-5011.

Orimo, A., Gupta, P.B., Sgroi, D.C., Arenzana-Seisdedos, F., Delaunay, T., Naeem, R., Carey, V.J., Richardson, A.L., and Weinberg, R.A. 2005. Stromal fibroblasts present in invasive human breast carcinomas promote tumor growth and angiogenesis through elevated SDF-1/CXCL12 secretion. Cell 121: 335-348.

Otani, A., Takagi, H., Oh, H., Koyama, S., Ogura, Y., Matumura, M., and Honda, Y. 2002. Vascular endothelial growth factor family and receptor expression in human choroidal neovascular membranes. Microvasc. Res. 64: 162-169.

Oyama, F., Hirohashi, S., Shimosato, Y., Titani, K., and Sekiguchi, K. 1989. Deregulation of alternative splicing of fibronec- tin pre-mRNA in malignant human liver tumors. J. Biol. Chem. 264: 10331-10334.

Pelham, R.J., Rodgers, L., Hall, I., Lucito, R., Nguyen, K.C., Navin, N., Hicks, J., Mu, D., Powers, S., Wigler, M., et al. 2006. Identification of alterations in DNA copy number in host stromal cells during tumor progression. Proc. Natl. Acad. Sci. 103: 19848-19853.

Perri, S.R., Annabi, B., and Galipeau, J. 2007. Angiostatin inhibits monocyte/macrophage migration via disruption of actin cytoskeleton. FASEB J. 21: 3928-3936.

Pinner, S. and Sahai, E. 2008. PDK1 regulates cancer cell motility by antagonising inhibition of ROCK1 by RhoE. Nat. Cell Biol. 10: 127-137.

Pittenger, M.F., Mackay, A.M., Beck, S.C., Jaiswal, R.K., Douglas, R., Mosca, J.D., Moorman, M.A., Simonetti, D.W., Craig, S., and Marshak, D.R. 1999. Multilineage potential of adult human mesenchymal stem cells. Science 284: 143-147.

Pollard, J.W. 2004. Tumour-educated macrophages promote tumour progression and metastasis. Nat. Rev. Cancer 4: 71-78.

Porcile, C., Bajetto, A., Barbero, S., Pirani, P., and Schettini, G. 2004. CXCR4 activation induces epidermal growth factor receptor transactivation in an ovarian cancer cell line. Ann. N. Y. Acad. Sci. 1030: 162-169.

Rafii, S. and Lyden, D. 2003. Therapeutic stem and progenitor cell transplantation for organ vascularization and regeneration. Nat. Med. 9: 702-712.

Rafii, S. and Lyden, D. 2006. S100 chemokines mediate bookmarking of premetastatic niches. Nat. Cell Biol. 8: 13211323.

Rafii, S. and Lyden, D. 2008. Cancer. A few to flip the angiogenic switch. Science 319: 163-164.

Robinson, S.C., Scott, K.A., and Balkwill, F.R. 2002. Chemokine stimulation of monocyte matrix metalloproteinase- 9 requires endogenous TNF- $\alpha$. Eur. J. Immunol. 32: 404-412.

Sappino, A.P., Skalli, O., Jackson, B., Schurch, W., and Gabbiani, G. 1988. Smooth-muscle differentiation in stromal cells of malignant and non-malignant breast tissues. Int. J. Cancer 41: 707-712.

Scholl, S.M., Pallud, C., Beuvon, F., Hacene, K., Stanley, E.R., Rohrschneider, L., Tang, R., Pouillart, P., and Lidereau, R. 1994. Anti-colony-stimulating factor-1 antibody staining in primary breast adenocarcinomas correlates with marked inflammatory cell infiltrates and prognosis. J. Natl. Cancer Inst. 86: 120-126.

Schor, S.L., Ellis, I.R., Jones, S.J., Baillie, R., Seneviratne, K., Clausen, J., Motegi, K., Vojtesek, B., Kankova, K., Furrie, E., et al. 2003. Migration-stimulating factor: A genetically truncated onco-fetal fibronectin isoform expressed by carcinoma and tumor-associated stromal cells. Cancer Res. 63: 88278836.

Shojaei, F., Wu, X., Malik, A.K., Zhong, C., Baldwin, M.E., Schanz, S., Fuh, G., Gerber, H.P., and Ferrara, N. 2007. Tumor refractoriness to anti-VEGF treatment is mediated by

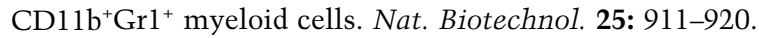

Sica, A. and Bronte, V. 2007. Altered macrophage differentiation and immune dysfunction in tumor development. J. Clin. Invest. 117: 1155-1166.

Sica, A., Schioppa, T., Mantovani, A., and Allavena, P. 2006. Tumour-associated macrophages are a distinct M2 polarised population promoting tumour progression: Potential targets of anti-cancer therapy. Eur. J. Cancer 42: 717-727.

Sinha, P., Clements, V.K., and Ostrand-Rosenberg, S. 2005. Reduction of myeloid-derived suppressor cells and induction of M1 macrophages facilitate the rejection of established metastatic disease. J. Immunol. 174: 636-645.

Sipkins, D.A., Wei, X., Wu, J.W., Runnels, J.M., Cote, D., 
Wels et al.

Means, T.K., Luster, A.D., Scadden, D.T., and Lin, C.P. 2005. In vivo imaging of specialized bone marrow endothelial microdomains for tumour engraftment. Nature 435: 969-973.

Stuelten, C.H., DaCosta Byfield, S., Arany, P.R., Karpova, T.S., Stetler-Stevenson, W.G., and Roberts, A.B. 2005. Breast cancer cells induce stromal fibroblasts to express MMP-9 via secretion of TNF- $\alpha$ and TGF- $\beta$. J. Cell Sci. 118: 2143-2153.

Sugimoto, H., Mundel, T.M., Kieran, M.W., and Kalluri, R. 2006. Identification of fibroblast heterogeneity in the tumor microenvironment. Cancer Biol. Ther. 5: 1640-1646.

Sun, Y.X., Wang, J., Shelburne, C.E., Lopatin, D.E., Chinnaiyan, A.M., Rubin, M.A., Pienta, K.J., and Taichman, R.S. 2003. Expression of CXCR4 and CXCL12 (SDF-1) in human prostate cancers (PCa) in vivo. J. Cell. Biochem. 89: 462-473.

Thiery, J.P. 2002. Epithelial-mesenchymal transitions in tumour progression. Nat. Rev. Cancer 2: 442-454.

Tlsty, T.D. 1998. Cell-adhesion-dependent influences on genomic instability and carcinogenesis. Curr. Opin. Cell Biol. 10: 647-653.

Tuck, A.B., Hota, C., Wilson, S.M., and Chambers, A.F. 2003. Osteopontin-induced migration of human mammary epithelial cells involves activation of EGF receptor and multiple signal transduction pathways. Oncogene 22: 1198-1205.

Venneri, M.A., De Palma, M., Ponzoni, M., Pucci, F., Scielzo, C., Zonari, E., Mazzieri, R., Doglioni, C., and Naldini, L. 2007. Identification of proangiogenic TIE2-expressing monocytes (TEMs) in human peripheral blood and cancer. Blood 109: 5276-5285.

Voswinckel, R., Ziegelhoeffer, T., Heil, M., Kostin, S., Breier, G., Mehling, T., Haberberger, R., Clauss, M., Gaumann, A., Schaper, W., et al. 2003. Circulating vascular progenitor cells do not contribute to compensatory lung growth. Circ. Res. 93: 372-379.

Wai, P.Y. and Kuo, P.C. 2004. The role of Osteopontin in tumor metastasis. J. Surg. Res. 121: 228-241.

Wolf, K., Wu, Y.I., Liu, Y., Geiger, J., Tam, E., Overall, C., Stack, M.S., and Friedl, P. 2007. Multi-step pericellular proteolysis controls the transition from individual to collective cancer cell invasion. Nat. Cell Biol. 9: 893-904.

Wyckoff, J.B., Wang, Y., Lin, E.Y., Li, J.F., Goswami, S., Stanley, E.R., Segall, J.E., Pollard, J.W., and Condeelis, J. 2007. Direct visualization of macrophage-assisted tumor cell intravasation in mammary tumors. Cancer Res. 67: 2649-2656.

Xian, X., Hakansson, J., Stahlberg, A., Lindblom, P., Betsholtz, C., Gerhardt, H., and Semb, H. 2006. Pericytes limit tumor cell metastasis. J. Clin. Invest. 116: 642-651.

Yang, L., DeBusk, L.M., Fukuda, K., Fingleton, B., Green-Jarvis, B., Shyr, Y., Matrisian, L.M., Carbone, D.P., and Lin, P.C. 2004. Expansion of myeloid immune suppressor $\mathrm{Gr}^{+} \mathrm{CD} 11 \mathrm{~b}^{+}$ cells in tumor-bearing host directly promotes tumor angiogenesis. Cancer Cell 6: 409-421.

Yang, L., Huang, J., Ren, X., Gorska, A.E., Chytil, A., Aakre, M., Carbone, D.P., Matrisian, L.M., Richmond, A., Lin, P.C., et al. 2008. Abrogation of TGF $\beta$ signaling in mammary carcinomas recruits $\mathrm{Gr}-1^{+} \mathrm{CD} 11 \mathrm{~b}^{+}$myeloid cells that promote metastasis. Cancer Cell 13: 23-35.

Ziegelhoeffer, T., Fernandez, B., Kostin, S., Heil, M., Voswinckel, R., Helisch, A., and Schaper, W. 2004. Bone marrow-derived cells do not incorporate into the adult growing vasculature. Circ. Res. 94: 230-238. 


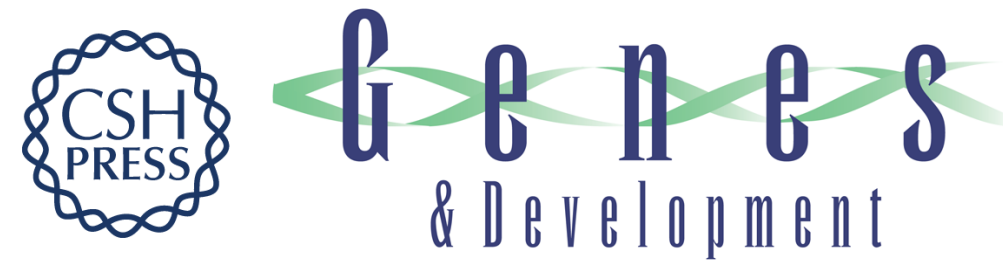

\section{Migratory neighbors and distant invaders: tumor-associated niche cells}

Jared Wels, Rosandra N. Kaplan, Shahin Rafii, et al.

Genes Dev. 2008, 22:

Access the most recent version at doi:10.1101/gad.1636908

References This article cites 150 articles, 55 of which can be accessed free at: http://genesdev.cshlp.org/content/22/5/559.full.html\#ref-list-1

License

Email Alerting Receive free email alerts when new articles cite this article - sign up in the box at the top Service right corner of the article or click here.

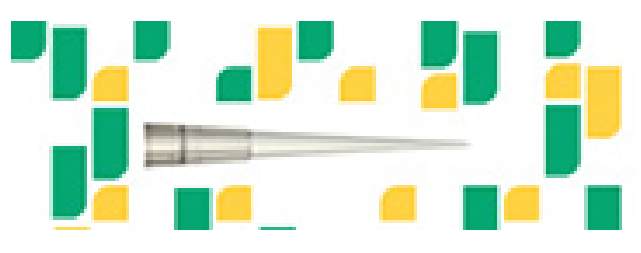

Focused on your science. 